\title{
Tropospheric Circulation Variability over Central and Southern South America
}

\author{
Oscar A. Frumento1, Vicente R. Barros ${ }^{2}$ \\ ${ }^{1}$ Centro Nacional Patagónico CNP (CONICET), Puerto Madryn, Argentina \\ ${ }^{2}$ Centro de Investigaciones del Mar y la Atmósfera CIMA (CONICET/UBA), Buenos Aires, Argentina \\ Email: oscar@cenpat-conicet.gob.ar
}

Received 22 October 2014; revised 23 November 2014; accepted 2 December 2014

Copyright (C) 2014 by authors and Scientific Research Publishing Inc.

This work is licensed under the Creative Commons Attribution International License (CC BY). http://creativecommons.org/licenses/by/4.0/

(c) $\underset{\mathrm{EY}}{\mathrm{Br}}$ Open Access

\begin{abstract}
Combined Empirical Orthogonal Function Analysis of low-level atmospheric circulation after filtering the synoptic scale was performed for the period 1981-2006 over Central and Southern South America. Modes with 40 and near 70 days frequency associated with swings in longitude of the South Pacific and South Atlantic Ocean heights were identified. Their extreme values were related to drought and to high anomalous precipitation associated to floods in South East South America (SESA). These modes were independent of other sources of variability of the Southern Hemisphere atmosphere, namely MJO (Madden-Julian Oscillation), ENSO (El Niño Southern Oscillation) and AAO (Antarctic Oscillation). Mode one, which in its positive phase has a circulation similar to the mean winter, has a trend that explains part of the winter warming observed since 1980's in Central and Eastern Argentina. Variance was calculated for the intra-annual variability, the one associated to the inter-annual variability including trends and jumps, and that of the annual cycle. The partition of the total variance was roughly $70 \%, 10 \%$ and $20 \%$ respectively. This partition implies that predictability of the regional climate is more critically dependent on the predictability of the intra-annual variability than of the inter-annual variability.
\end{abstract}

\section{Keywords}

Tropospheric Circulation, Variability, SESA

\section{Introduction}

Southern and Central South America (SCSA), situated at subtropical and mid latitudes, has a climate with a strong seasonal as well as synoptic and intraseasonal variability. The seasonal variation of the tropospheric flow over most of central South America, east of the Andes Mountains, and its association with the precipitation re- 
gime have been characterized as a monsoon-like circulation (the so-called South American Monsoon System, SAMS) [1], of which a review can be found in [2].

The upper tropospheric-circulation over SCSA and neighboring areas also presents a marked seasonal variability of the subtropical jet [3] and of the western circulation that extends over lower latitudes in winter. During the warm part of the year, in the upper troposphere there is an anticyclonic circulation known as the Bolivian High (BH) [4]-[7] over the subtropical west, resulting from the diabatic heating liberated by the monsoon activity and a trough in the northeast [8]-[10].

In the lower troposphere, a prominent circulation feature is the transport of moisture from the tropical Atlantic ocean to the Amazon basin that enhances the convective activity [11] [12] and from this basin, but also in some cases from the adjacent southern Atlantic Ocean, a southward flow towards the extratropics, in which it is sometimes embedded the South American low level jet (SALLJ) [13] [14].

Other relevant feature during the warmer months is the South Atlantic Convergence Zone (SACZ) [15] [16], an extension of the convection in central and northern SA into the east of Brazil and the neighboring ocean. In the intra-seasonal time scale, a dipolar pattern characterizes the summer precipitation variability in Southeast South America (SESA). In one of its phases, there is enhanced precipitation over the SACZ accompanied by decreased rainfall in the subtropical plains to the south of the SACZ region; in the opposite phase, the humid flow from the tropical continent instead of flowing to the SACZ region diverts into the subtropics containing sometimes a low level jet [17]-[19].

Low-level wind regimes over SCSA are linked to break and active phases of SAMS affecting the distribution of convection in SESA and, hence, of precipitation [20]. Part of intra-seasonal variability affecting CSSA is related to the Madden-Julian Oscillation (MJO) [21], which modulates CSSA convection through its tropical displacement [22].

Other source of intraseasonal variability comes from the leading mode of atmospheric variability in the Southern Hemisphere, the Southern Hemispheric Annular Mode (SAM) that has also inter-annual variability [23]-[26] with a wavenumber-3 signature. It is alternately known as the high-latitude mode [27] and the Antarctic Oscillation [28]. Over SESA, the SAM is related with precipitation variability in winter and late spring contributing to explain part of the inter-annual variability not associated to ENSO events [29]. Vasconcellos and Cavalcanti [30] associated extreme precipitation events in SESA with anomalous circulation in the region, forced by a PSA-like wave train [31] intensified by the SAM.

There are several studies on inter-annual variability of precipitation and its association with the El NiñoSouthern Oscillation (ENSO). Warm (cold) episodes are associated with generally wet (dry) conditions over SESA during November to April, but with differences between sub regions, calendar months and particular events [32]-[42]. Also during the warmer months, anomalies of SST over the adjacent South Atlantic have been related to precipitation variability over SESA; above (below) average SST in the southwestern portion of the subtropical Atlantic with wet (dry) conditions [19] [43] [44].

There is more work on intra seasonal and inter-annual variability features not addressed here; however, this brief summary indicates that in many cases the known features of the intra seasonal atmospheric variability in SCSA have relations between them and with modes of the inter-annual variability. The main objective of this paper is to describe the modes of the regional climate variability, especially those not yet known. Other objective is to quantify the low level atmospheric variability in the intra seasonal scale and how this variability compares with that of the annual cycle and of the inter-annual scale. It is also addressed the trends or changes of the seasonal and intra seasonal atmospheric variability, especially because during the last decades the annual precipitation went through important changes in great part of SCSA, whose causes are not yet fully understood [45]-[47]. To theses aims, a principal component analysis of the low level circulation was performed over a domain centered in CSSA, which does not extend to far beyond this region.

The outline of the paper is as follows: the next section describes data sets and methodology. The first six modes are analyzed in Section 3. The partition of variance among the frequencies corresponding to the annual cycle, the inter-annual and the intra-annual variability which are no part of the annual cycle as well as time scales, changes and trends of the regional circulation variability are discussed in Section 4. Summary and concluding remarks are given in Section 5.

\section{Data and Methodology}

Tropospheric data from radiosonde in South America (SA) were, and still are, rather sparse in space and in most 
of the cases have only daily frequency. Hence, satellite information greatly contributed to improve the quality of reanalysis and consequently, this study focuses on a period that started near the time when the satellite information became more reliable [48] [49]. Therefore, this study covers the period 1 January 1981 to 31 December 2006. Data used was daily zonal and meridional wind components at $850 \mathrm{hPa}$, streamfunction and divergence fields at $200 \mathrm{hPa}$ and mean sea level pressure obtained from National Center for Environmental Prediction/Department of Energy (NCEP/DOE) Atmospheric Model Intercomparison Project (AMIP) II Reanalyses (NCEP-2) [50]. The horizontal resolution of this data is $2.5^{\circ} \times 2.5^{\circ}$ (latitude and longitude).

Daily precipitation data set gridded by the NCEP Climate Prediction Center (CPC) in $1^{\circ}$ latitude-longitude resolution arrays from local observation stations was used for the continental region between $60^{\circ} \mathrm{S}$ and $15^{\circ} \mathrm{N}$. Monthly indexes of ENSO, MJO and AAO were obtained from NWS Climate Prediction Center from its Web site. The one degree latitude-longitude grid NOAA Optimum Interpolation Sea Surface Temperature (SST) V2, provided by the NOAA/OAR/ESRL PSD, Boulder, Colorado, USA, from their Web site at

http://www.esrl.noaa.gov/psd/, was linearly interpolated to daily values from the original weekly data [51]. Monthly surface temperature taken from the Climate Research Unit, East Anglia (CRU) was used to address winter trends in part of Argentina and its relationship with changes in low level circulation.

Although OLR fields are not shown in the paper, daily OLR data from the National Oceanic and Atmospheric Administration/Cooperative Institute for Research in Environmental Sciences Climate Diagnostics Center [52] with $2.5^{\circ}$ latitude-longitude grid were used in the analysis as a proxy of large scale convective activity.

All fields were filtered using the Lanczos filtering [53] with 152 weights. The filter was applied to only retain frequencies above 10 days, avoiding the contributions of the synoptic-scale. Combined unrotated EOFs (cEOFs) based on the covariance matrix was applied to zonal and meridional $850 \mathrm{hPa}$ daily wind fields anomalies for the entire length of data as a tool to identify the main spatial and temporal patterns of the low level tropospheric circulation over CSSA. The 850 wind field is an indicator of the low level temperature and moist advection, which in the region is related to the precipitation field. It is worth to stress that the annual cycle was not removed and therefore it is largely represented by the first EOF. This was made to allow the comparison of its contribution to variability with those of the intra-annual and inter-annual scale and explore its possible changes along the period of the study.

The domain of cEOFs computation was confined to $5^{\circ} \mathrm{N}-40^{\circ} \mathrm{S}, 90^{\circ} \mathrm{W}-30^{\circ} \mathrm{W}$ (Figure 1). The election of the domain was made to capture the modes dominated by the variability of the troposphere circulation over SCSA, while also keeping the neighboring parts of the Pacific and Atlantic oceans because both subtropical highs play an important role on the SCSA climate. However, the circulation patterns associated to the main modes of SCSA tropospheric variability were composed over a wider region than that used in the cEOFs determination, namely in the $0^{\circ} \mathrm{S}-60^{\circ} \mathrm{S}, 30^{\circ} \mathrm{W}-160^{\circ} \mathrm{W}$ domain.

Daily PCs were normalized according to their values over the study period. $850 \mathrm{hPa}$ wind daily fields with PCs larger (smaller) than one standard deviation, were composed to facilitate the view of the average field associated with the positive and negative phase of each cEOF. Similarly the same type of composition was also done for sea level pressure (shown in the same map of $850 \mathrm{hPa}$ ), $200 \mathrm{hPa}$ stream function and divergence fields and in the case of precipitation, only over the continent. These spatial compositions have the advantage of showing the actual fields associated to the cEOF, which are not shown.

A multi-taper spectral method (MTM) was used on PCs time series to examine in more detail the spectrum of the PCs. MTM allows reducing the standard error of spectral frequency estimates by using a small set of tapers and estimating the spectrum as a weighted average [54] [55]. In this study three tapers were used to provide reasonable frequency resolution and sufficient degree of freedom in the spectrum estimate.

\section{Results}

The appropriate number of modes of the cEOFs to retain was identified according the scree test [56] which consists in the visual exploration of graphical representation of the variance of eigenvalues. Based on this diagram six leading modes of the cEOFs explaining $61.1 \%$ of the variance were retained for analysis. The first mode has the spatial structure typical of the annual cycle ( $19.6 \%$ of the variance), but is not the only one contributing to this cycle. The following 4 modes, account for $12.4 \%, 10.0 \%, 7.5 \%$ and $6.1 \%$ of the variance respectively, while the sixth mode that carries important inter-annual variability explains only $5 \%$ of the variance.

Only at Modes 1, 3 and 5, the PC time series show a discernible annual periodicity to the visual inspection, 
Figure 2. However, all modes contribute to the annual cycle, Figure 3 and Figure 4. As background for the analysis of the modes, Figure 5 shows the annual average, summer (JFM) and winter (JJA months) of sea level pressure and low level $(850 \mathrm{hPa})$ circulation.

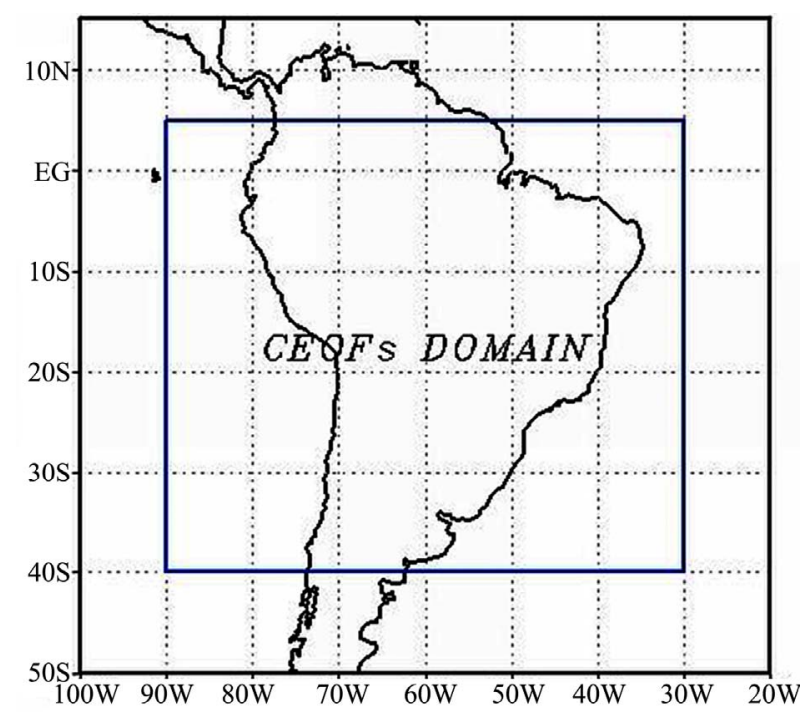

Figure 1. Domain of cEOFs computation (blue box).

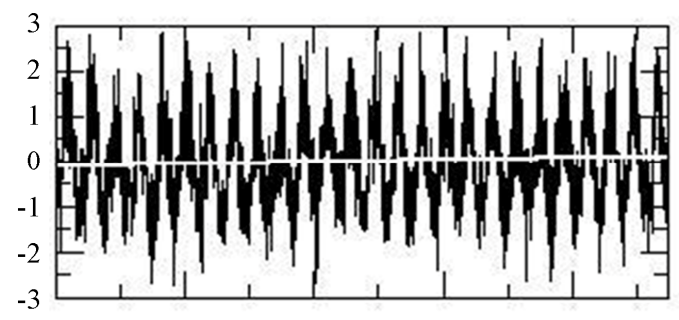

(a)

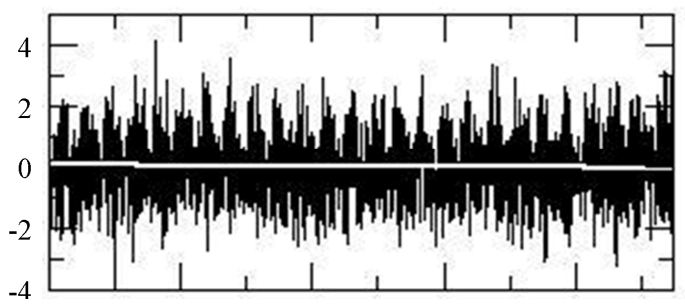

(c)

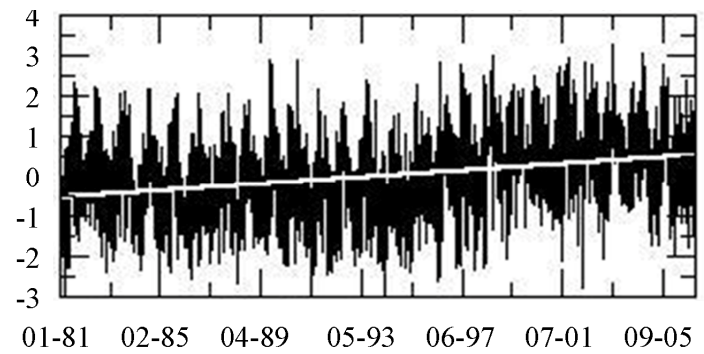

(e)

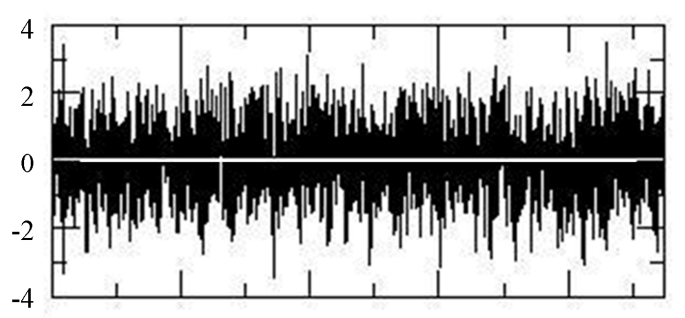

(b)

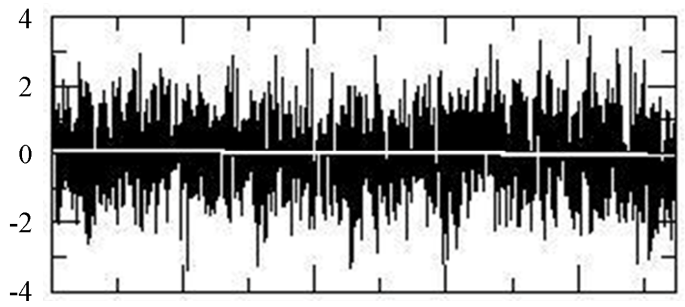

(d)

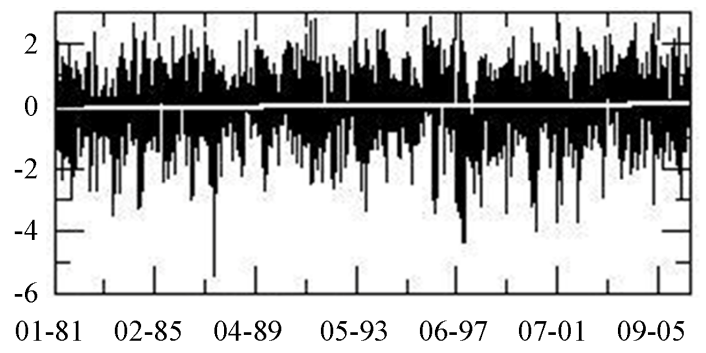

(f)

Figure 2. Normalized PC time series and trends (in white) of the six first cEOfs modes: (a) PC1; (b) PC2; (c) PC3; (d) PC4; (e) PC5 and (d) PC6. 


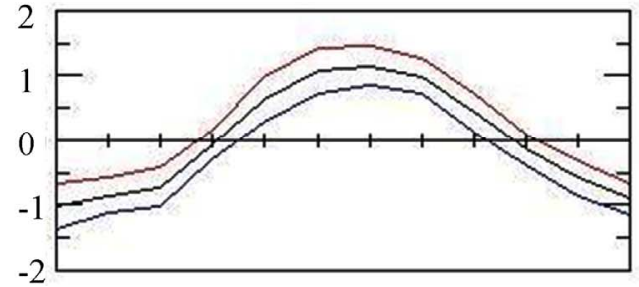

(a)

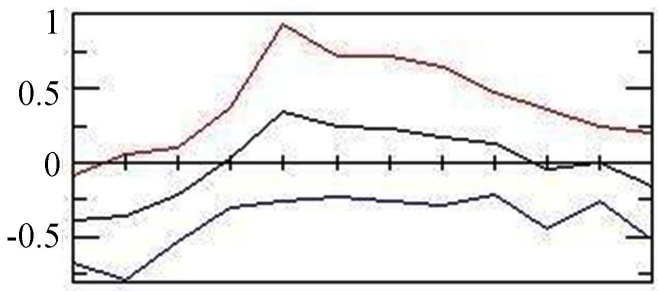

(c)

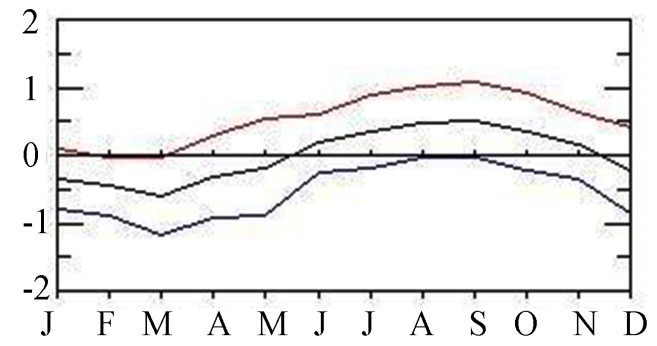

(e)

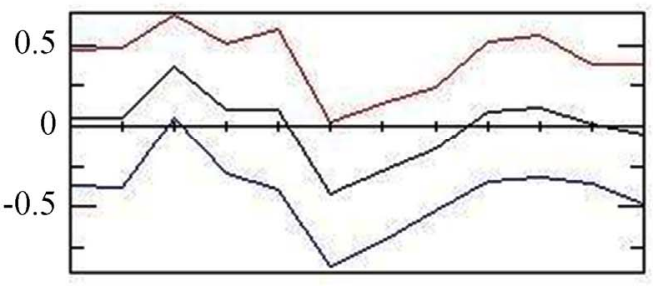

(b)

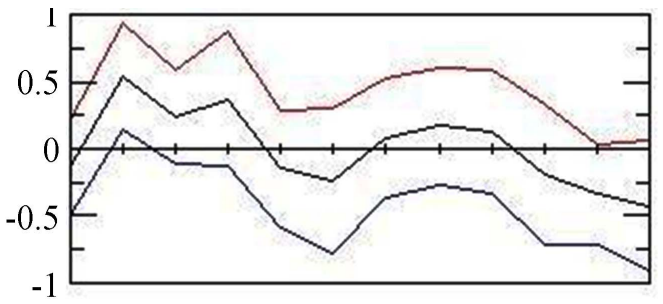

(d)

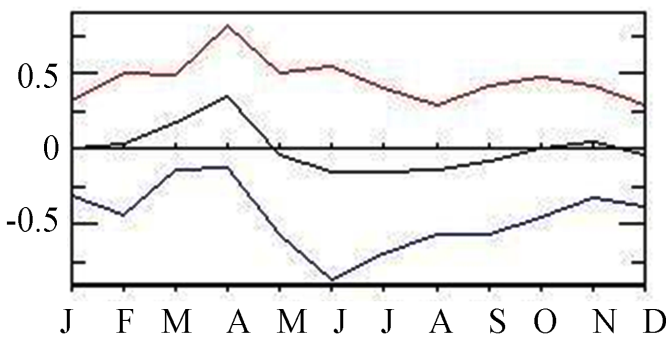

(f)

Figure 3. Annual cycle of normalized PC time series in black, $+1 \sigma$ in red and $-1 \sigma$ in blue.

\subsection{First Mode}

Figure 6(a) shows the composites of the positive phase of the first mode for $850 \mathrm{hPa}$ wind field and sea level pressure (SLP) that clearly resembles the typical winter time circulation with the subtropical Pacific anticyclone centered at $25^{\circ} \mathrm{S}$ and a significant intrusion of the Atlantic high over the continent (Figure 5(a)). However, differently from the average winter circulation, there is a strong northern flow over SESA and central Argentina.

Rather than depicting the low level circulation of the summer season, composites of negative phase of the first mode resemble only one phase of the enhanced SACZ, which is the main feature of the summer SESA variability [18]. That is, over central SA the low level flow is characterized by two branches, one coming from the tropical continent that converges with other coming along the Brazilian cost near $20^{\circ} \mathrm{S}$ (Figure 6(b)). More specifically, this low level circulation is observed when the SACZ is displaced northward of its mean position [57].

The upper level circulation pattern is presented through the anomalies of the stream function field at $200 \mathrm{hPa}$ respect of the mean annual value and the divergence field at this level (Figure 6(c) and Figure 6(d)). These fields have almost opposite patterns in the two phases. The positive one is consistent with the typical cool season circulation over the continent characterized by the equator ward displacement of the subtropical jet and the weakening of the westerly flow in middle and high latitudes of this sector of the Southern Hemisphere (Figure 6(c)). Their mean divergence field shows upper level convergence over most of Brazil, Peru, Paraguay, Bolivia and Northern Argentina associated to the dryness of the winter in this monsoonic region and a strong divergence in southern Chile associated to the winter precipitation over this part of the country and over the Andes Mountains. In the case of the negative phase, the western flow is weakened at low latitudes and intensified south of $50^{\circ} \mathrm{S}$ with respect to the annual average circulation, and there is an anticyclonic circulation at subtropical and tropical latitudes over the continent (Figure 6(d)). The $200 \mathrm{hPa}$ divergence field shows the pattern resulting of the convective conditions of the summer season over tropical Brazil that stretches over the Atlantic Ocean along the SACZ and of the associated subsidence southwest of the SACZ; in the southwest of the continent over Chile, 


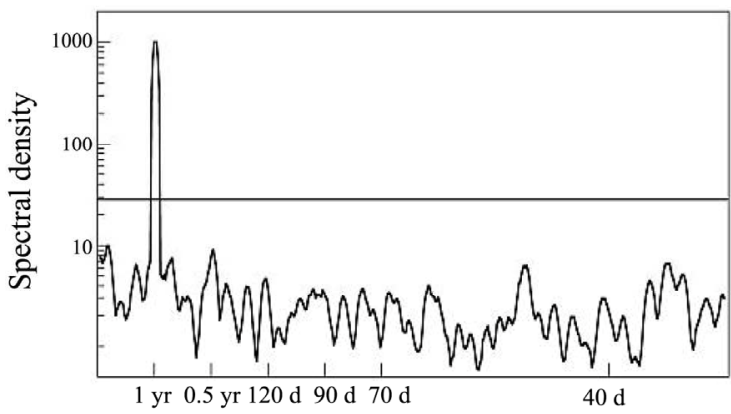

(a)

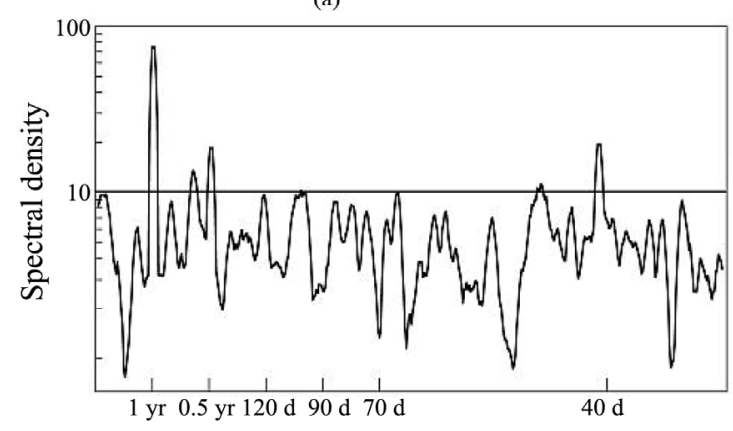

(c)

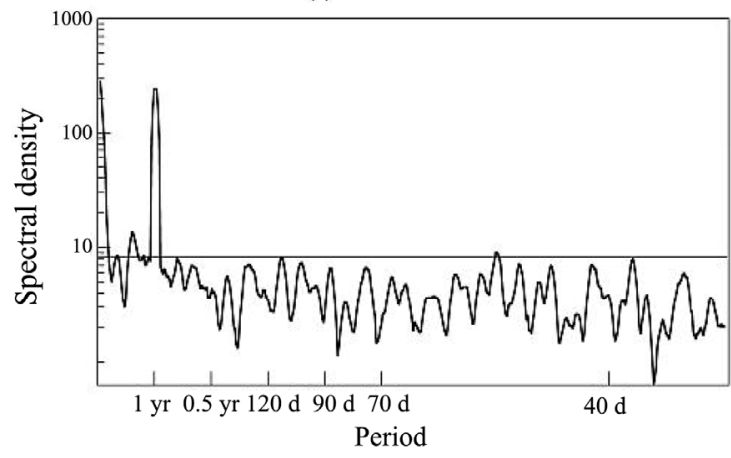

(e)

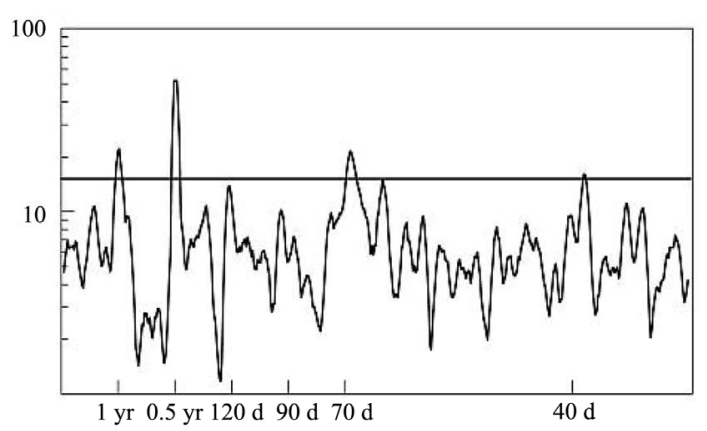

(b)

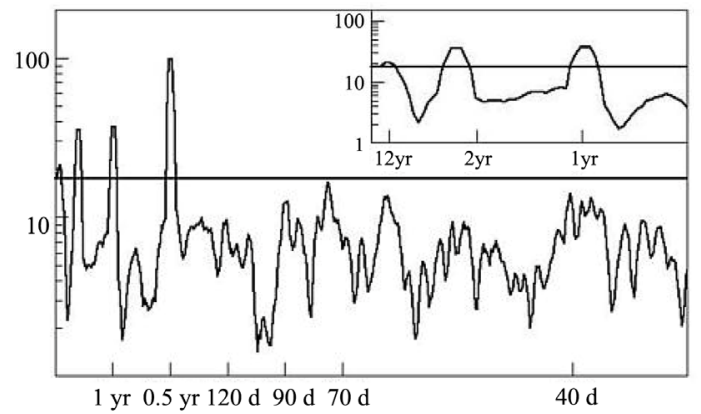

(d)

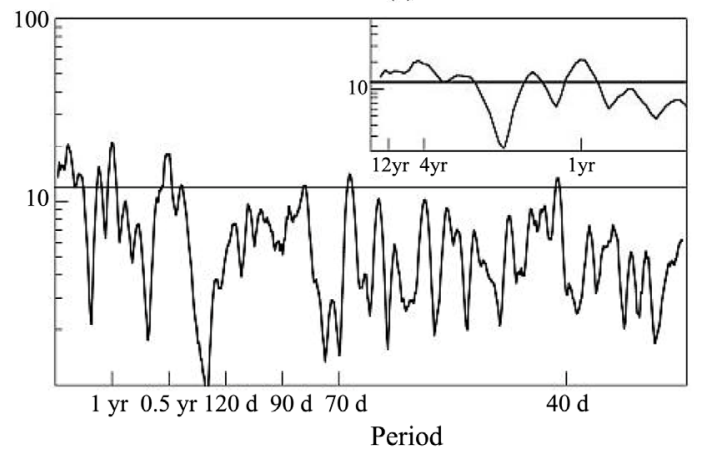

(f)

Figure 4. MTM spectrum of normalized PC time series: Mode 1 (a); Mode 2 (b); Mode 3 (c); Mode 4 (d); Mode 5 (e) and Mode 6 (f); for the Modes 4 and 6 detail of low frequency spectra is shown in the upper right corner.

the convergence at the upper troposphere is a feature consistent with the typical low precipitation of summer.

The compound of precipitation anomalies respect the corresponding annual average of the positive phase (not shown) is similar to the winter precipitation pattern with a maximum of precipitation in the south of Brazil and north of Uruguay along the southeast cost of SESA and with the typical winter dryness of the monsoon in central Brazil, Paraguay Bolivia, and most of north and central Argentina. More interesting is the composite field of the precipitation anomalies with respect to the corresponding daily averages, which reveals the differences with respect to the average winter; there is an overall enhancement of the precipitation spatial differences with less precipitation over all the region dominated by the monsoon dryness and more precipitation in central and southern Chile and the northwestern Argentinean Patagonia (Figure 6(e)).

The exception to this enhancement is over the region of the maximum winter precipitation over SESA where there is a center with a maximum decrease with respect the average winter precipitation. The composite mean precipitation of the negative phase are characterized by large values over central Brazil that extends over the SACZ region (not shown), while its composite of anomalies respect to daily means reveals the typical field of the positive phase of the SACZ with enhancement of rainfall over its region and negative anomalies over northeast and Central Argentina, Uruguay and south of Paraguay and Brazil (Figure 6(f)). 

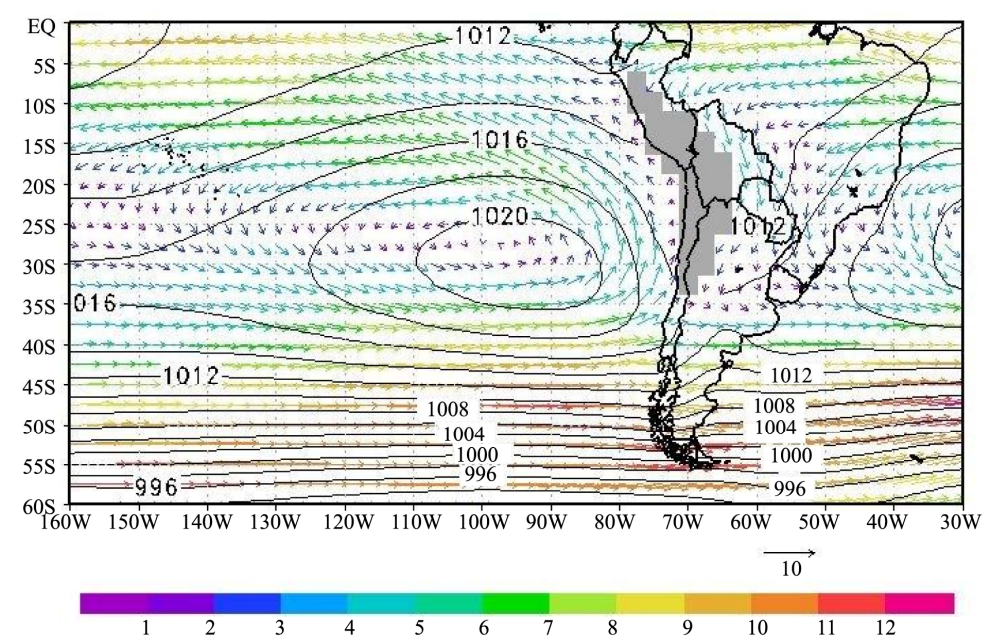

(a)
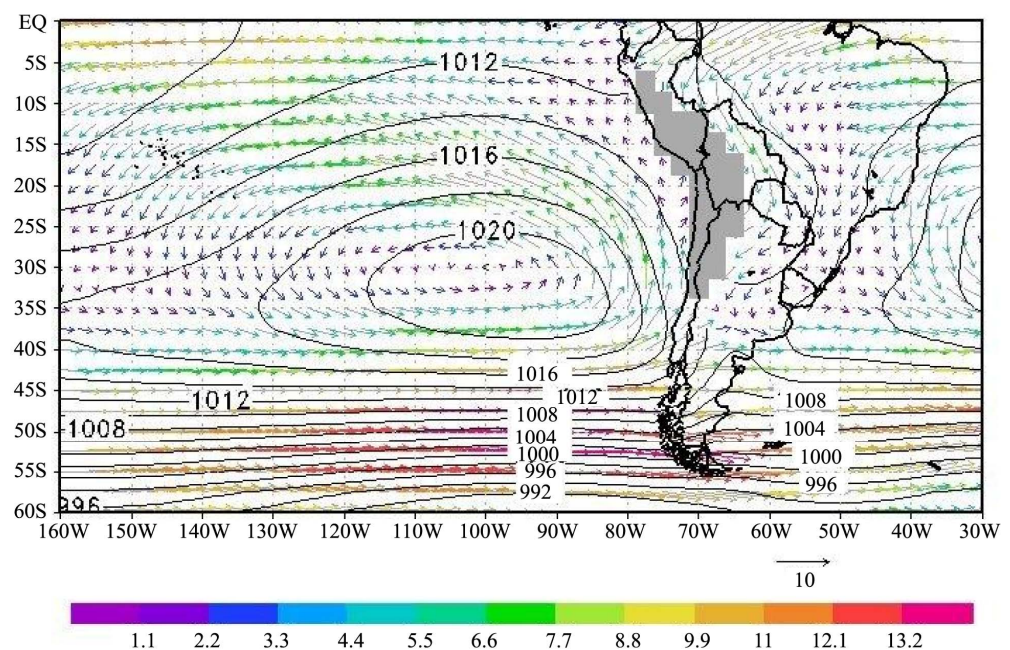

(b)
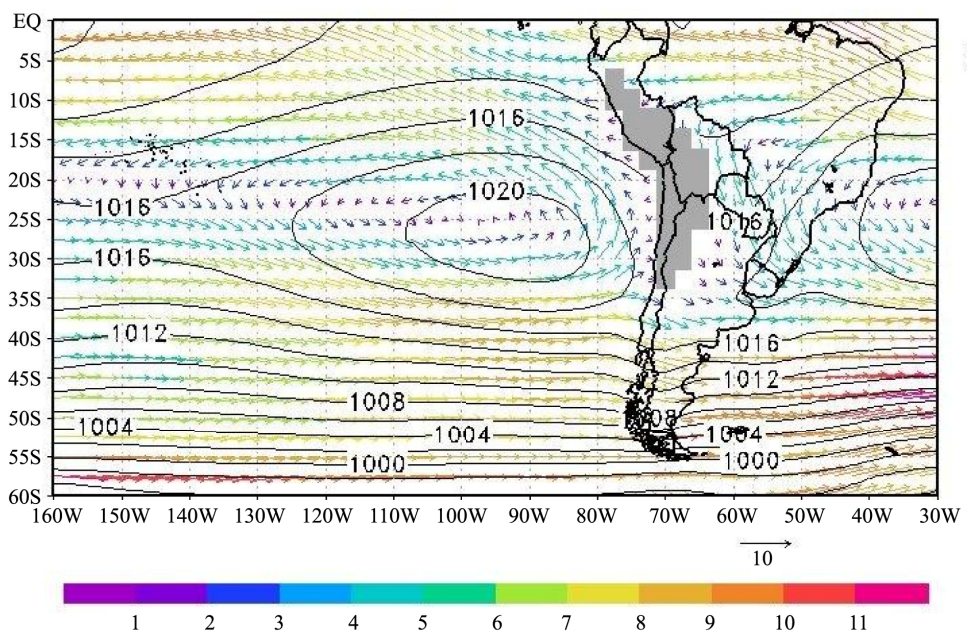

(c)

Figure 5. Mean 1981-2006 sea level pressure (hPa) and 850-hPa wind field (m/s). (a) Annual; (b) Winter (JJA); and (c) Summer (DJF). 


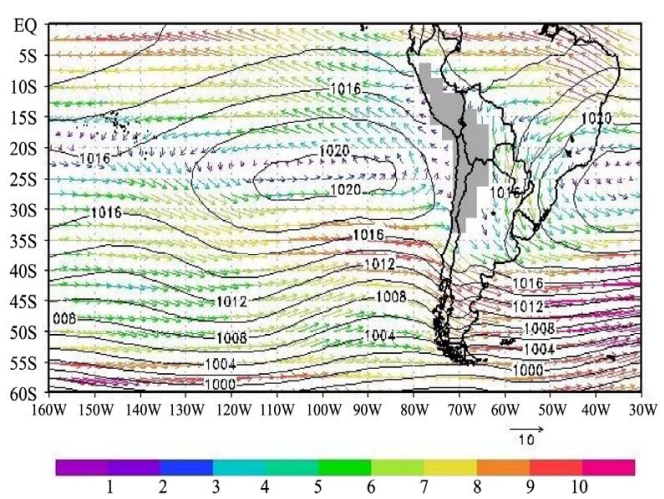

(a)

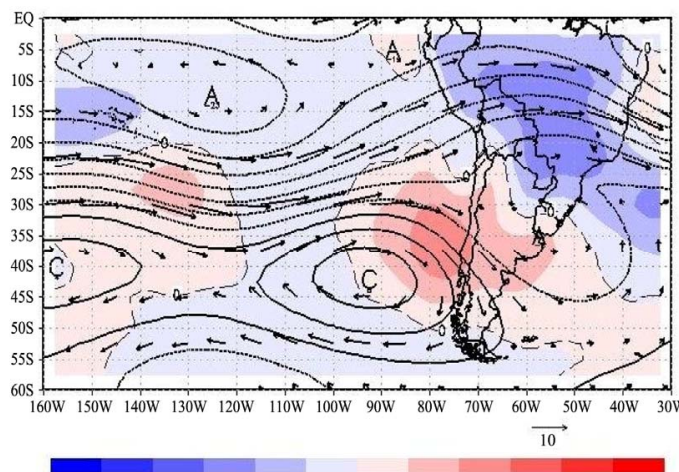

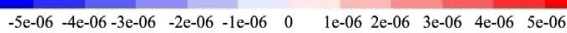

(c)

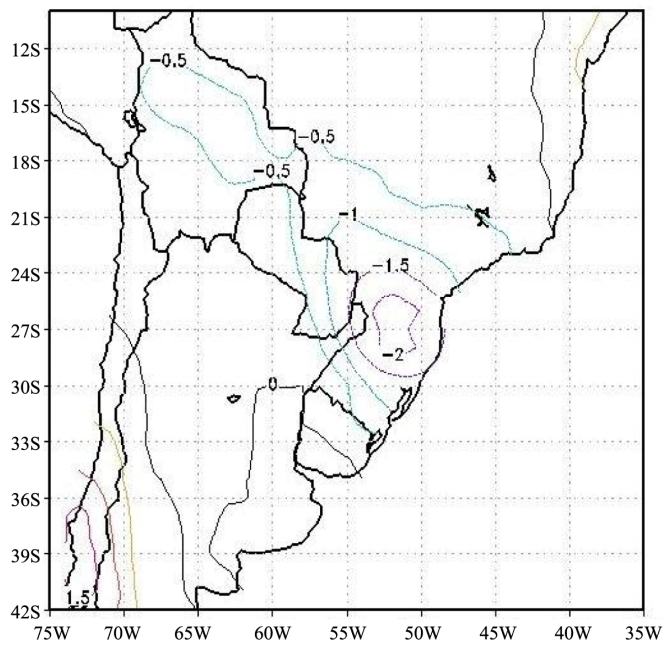

(e)

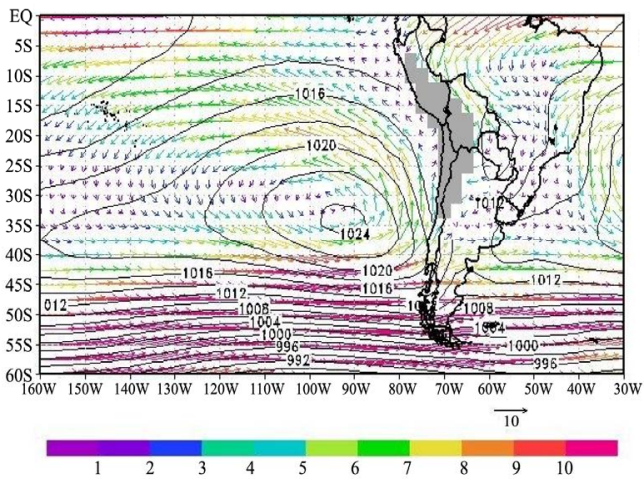

(b)

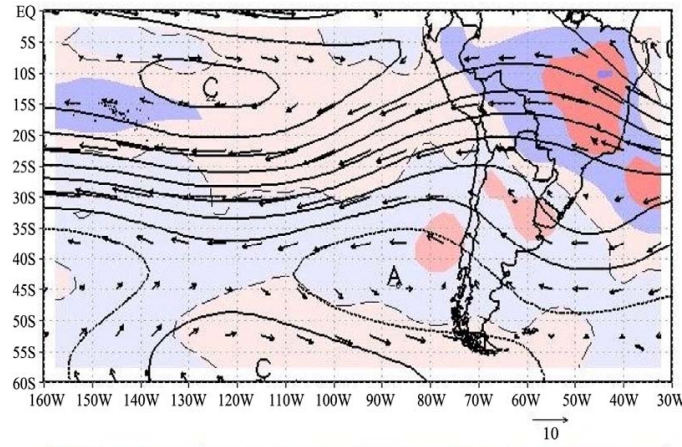

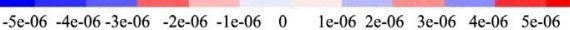

(d)

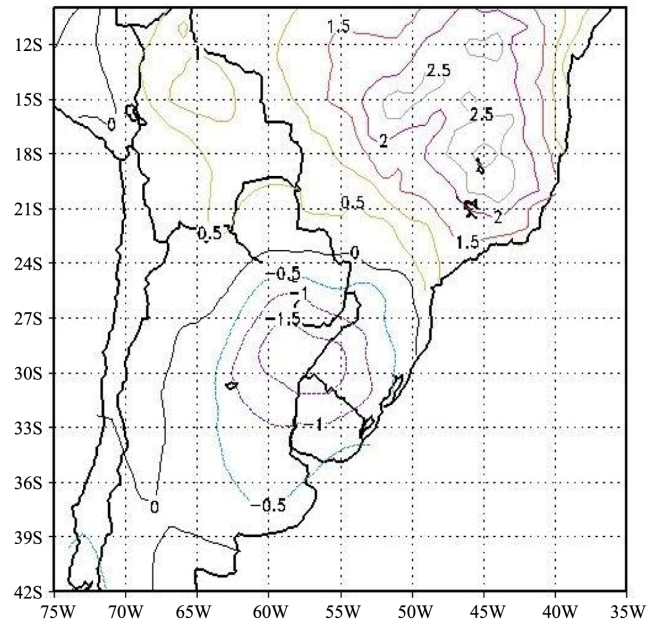

(f)

Figure 6. Positive (left) and negative (right) phase composites of Mode 1 of sea level pressure and $850 \mathrm{hPa}$ wind components (top); anomalies of stream function (C: cyclonic; A: anticyclonic circulation) and divergence/convergence (light blue/ light red) fields at $200 \mathrm{hPa}$ (middle) and precipitation daily anomalies in $\mathrm{mm} /$ day (bottom). Sea level pressure in $\mathrm{hPa}$; wind components and wind anomalies in $\mathrm{m} / \mathrm{s}$.

\subsection{Second Mode}

This mode contributes to the annual cycle, especially at the semiannual harmonic. Its spectrum also shows energy randomly distributed in all frequencies, but with two significant peaks at frequencies corresponding to 40 and 70 days (Figure 4(b)). 
The low level circulation corresponding to this mode shows a simultaneous swing of the two subtropical highs to the west in one phase and to the east in the other, which in addition are displaced southward in the phase when they are near the continent (Figure 7(a) and Figure 7(b)). In the positive phase, the Pacific high is extended westward and centered around $105^{\circ} \mathrm{W}$, while the western border of the Atlantic high is unusually displaced to the southwest (Figure 7(a)). Accompanying the shift of the Atlantic high, there is a flow from the
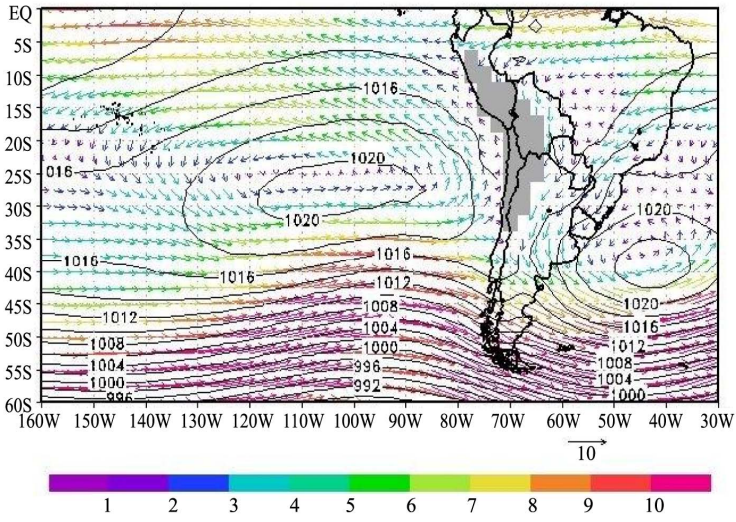

(a)

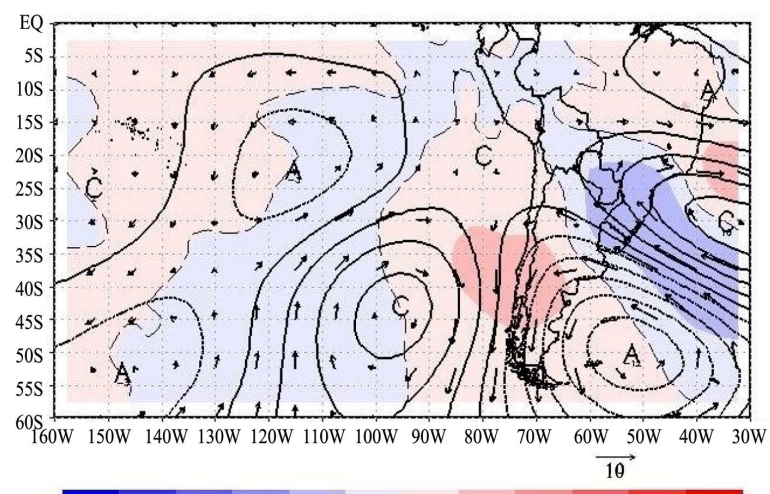

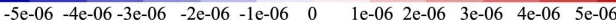

(c)

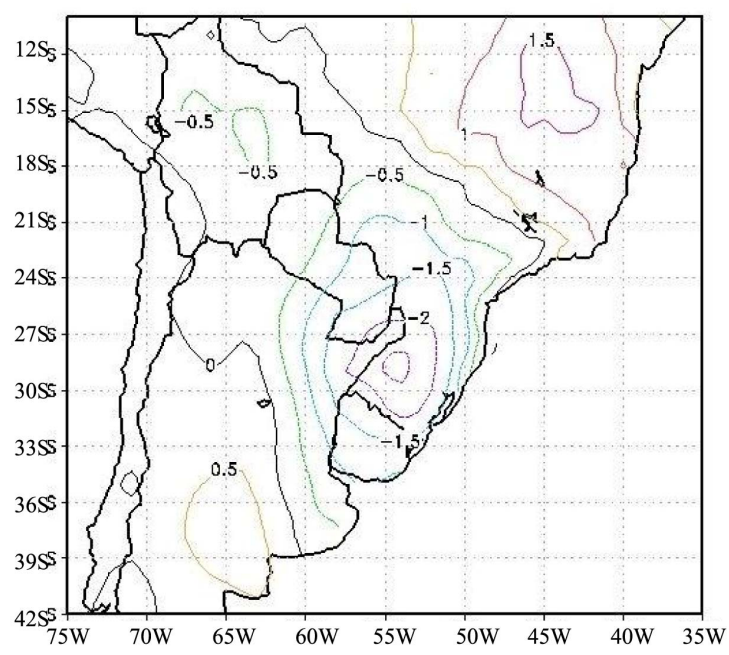

(e)
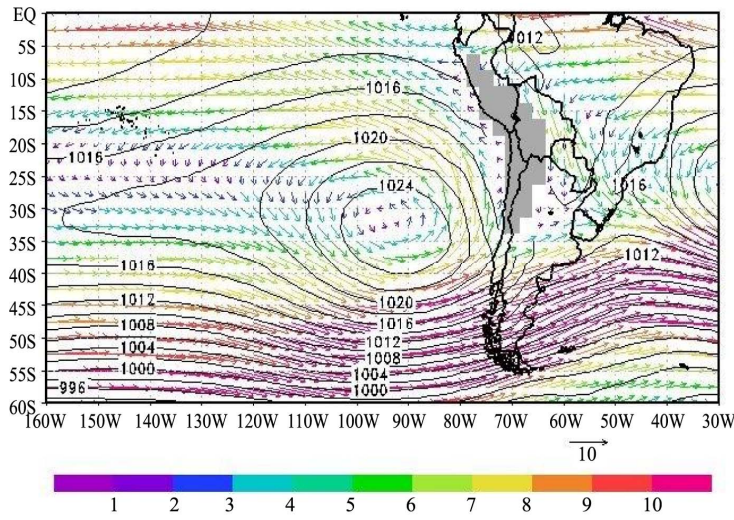

(b)

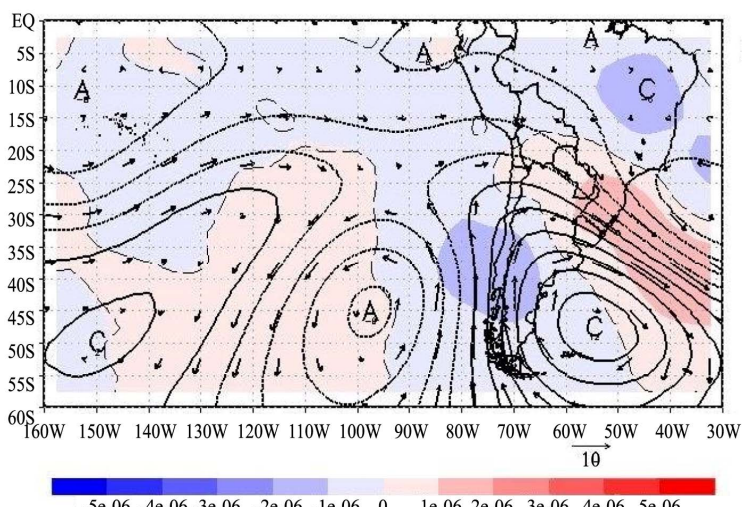

(d)

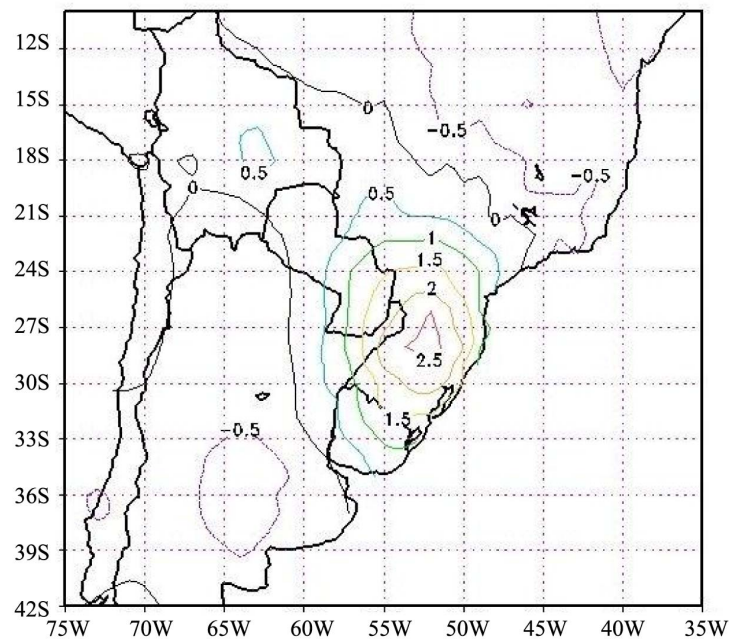

(f)

Figure 7. Same as Figure 6, but for Mode 2. 
northeast all over the southern part of the continent east of the Andes resulting from the merging of an easterly flow over the east coast of the continent and a southward flow from the tropical continent that advects moist and warm air over the SESA and central Argentina. In the negative phase, the Pacific high is displaced to the south, but also eastward of its mean position and intensified (Figure 7(b)). The Atlantic high circulation accompanies the displacement to the east; its flow from Atlantic Ocean merges with one from the tropical continent converging towards SESA and then with the westerly flow over the Atlantic Ocean. This flow over SESA is typical of the enhanced SACZ phase when is displaced southward of its mean position [57], but takes place all year round with more frequency in winter (Figure 3).

The upper level flow shows in both phases a wave trend in mid latitudes originated in the subtropical Pacific Ocean (Figure 7(c) and Figure 7(d)). The convergence at the upper level is consistent with the wave train with convergence on SESA and divergence over Chile and west Argentina.

The pattern of the negative phase is almost anti symmetric to that of the positive phase with a similar but opposite in phase wave train (Figure 7(d)). Over SESA, the Pacific South American (PSA) wave pattern favors cyclonic vorticity advection and enhancement of the westerly flow in upper levels.

The composites of daily precipitation anomalies show a clear opposite patterns between the two phases, which are consistent with the upper level convergence and stream function fields (Figure 7(e) and Figure 7(f)), as well with the moist advection that can be inferred from the low level flow.

PC2 neither has significant correlation with SST temperature (not shown) nor with any of the indexes that are known to have some influence on the SCSA climate, except with the AAO (Table 1). Their spatial features coincide at the latitude band between $40^{\circ} \mathrm{S}$ and $60^{\circ} \mathrm{S}$ over the southern tip of the SA continent and the adjacent oceans. However, the correlation of only 0.32 implies that, although related to the AAO, this second mode has most of its variability no related to it and it is basically an independent regional mode.

\subsection{Third Mode}

The third mode shares with the second mode the swing of the subtropical highs to the west in one phase and to the east in the other; the upper level circulation also presents a similar wave train, but in quadrature with respect to the one of the second mode. It has significant peaks on the spectrum at approximately the same frequencies, i.e. annual and semi-annual, but with more importance in the annual harmonic; it also has energy randomly distributed in all frequencies with a significant peak at the frequency corresponding to 40 days and important ones between the 70/100 days periods (Figure 4(c)).

In the positive phase the Pacific high is shifted to the south-east of its average position and centered at $35^{\circ} \mathrm{S}$ $85^{\circ} \mathrm{W}$ with an axis ridge passing across the Andes and reaching part of the SESA; the Atlantic high is also displaced to the east and a broad trough is to the east of SESA with a westerly flow reaching latitudes as far north as $20^{\circ} \mathrm{S}$ over the eastern coastal region (Figure 8(a)). This pattern is consistent with a synoptic situation of one or more cold frontal intrusions that penetrate the subtropical continent and remain nearly stationary for many days. According to Figure 3(b) and Table 1 this pattern occurs all the year round, but is more (less) common in

Table 1. Correlations between monthly climate indices and Modes 1 to 6 .

\begin{tabular}{|c|c|c|c|c|c|c|}
\hline & \multicolumn{6}{|c|}{ Mode } \\
\hline & $\mathrm{CP} 1$ & $\mathrm{CP} 2$ & CP3 & CP4 & CP5 & CP6 \\
\hline N12 & -0.05 & -0.01 & -0.03 & -0.12 & -0.06 & -0.37 \\
\hline N3 & 0.06 & -0.03 & -0.02 & -0.17 & -0.06 & -0.31 \\
\hline N34 & 0.09 & -0.04 & -0.02 & -0.21 & -0.10 & -0.26 \\
\hline N4 & 0.09 & -0.04 & -0.03 & -0.25 & -0.09 & -0.15 \\
\hline OAA & -0.08 & 0.32 & 0.14 & 0.17 & 0.20 & 0.01 \\
\hline MJ120 & -0.02 & -0.09 & 0.01 & 0.16 & 0.09 & 0.20 \\
\hline MJ40 & 0.03 & -0.14 & 0.01 & 0.22 & 0.14 & 0.28 \\
\hline MJ10 & 0.09 & -0.15 & 0.01 & 0.23 & 0.16 & 0.28 \\
\hline N12 & 0.06 & -0.03 & -0.02 & -0.17 & -0.06 & -0.31 \\
\hline N3 & 0.09 & -0.04 & -0.02 & -0.21 & -0.10 & -0.26 \\
\hline
\end{tabular}


winter (summer) when the cold fronts reach lower (only higher) latitudes more frequently. Opposite to the positive phase, the negative phase shows displacements to the west of both the Pacific and Atlantic highs (Figure 8(b)). This pattern resembles the summer pattern during the negative phase of the SACZ, but it may occur with less frequency all the year round whenever the intrusion of the Atlantic high circulation into the continent is accompanied by a southward flow from the tropical region towards subtropical latitudes.

In the positive phase, the upper-level pattern is characterized by an intensification of the subtropical jet over the continent and the neighboring oceans and a PSA like wave train pattern [31] [58] propagating southeastward first, and then turning northeastward from the $40^{\circ} \mathrm{S}-60^{\circ} \mathrm{S}$ latitude band (Figure 8(c)). Consistent with this pattern, the upper-level divergence field shows convergence over almost all the continent south of $10^{\circ} \mathrm{S}$, with exception of its more northern part, but the more important convergence is over the SESA (Figure 8(c)). In the negative phase the anomaly stream function shows again a wave trend propagating from the central Pacific Ocean with intense positive and negative centers over the southern east of Pacific Ocean and southern SA and SESA respectively (Figure 8(d)). The upper-level divergence extends from southeast Pacific Ocean to SESA, being more intense in this region, while over the oceanic SACZ there is a mean convergence indicating that convection is diminished (OLR compound not shown).

As expected, the composites of the anomalous precipitation patterns are consistent with the tropospheric circulation at both phases, depicting between them almost opposite patterns: in the positive (negative) phase there are negative (positive) anomalies over SESA and central Argentina and positive (negative) anomalies over the coastal region of the SACZ and over central Chile and southwestern Argentina (Figure 8(e) and Figure 8(f)).

The spectrum of this mode has, in addition to the annual and semiannual peaks, other significant peak near 40 days and a less conspicuous one, close in frequency at 47 days. This means that conditions with important contribution from one of the phases of this mode can sometimes persist almost stationary for near 20 or more days, favoring the hydrological stress (excess) in SESA when the positive (negative) phase is dominant. One example of the positive stationary phase were the periods of 5 to 25 of July 1996 and 12 to 26 of July 2000 when the patterns over southern SA were dominated by the third mode in its positive phase with semi stationary synoptic situations similar to the one depicted in Figure 8(a), accompanied with an upper ridge over central Argentina.

In the case of the negative phase, the upper tropospheric pattern corresponds to a trough extending from the Argentine Patagonia to central Chile that when remains stationary for about 20 or more days favors cyclonic vorticity advection, which may cause considerable precipitation over the south of SESA (Figure 8(f)). As an example to illustrate this point, it is worth to mention that the three more important peak floods of the Uruguay River at Salto Grande, situated at $33^{\circ} \mathrm{S}$ at the border between Argentina and Uruguay and whose catchment is all included in SESA region, correspond to cases of this stationary situation. All the three largest peaks occurred after a long period dominated by strong negative values of the third PC. The first peak in magnitude took place in July 21, 1983, soon after the period 26 June-14 July when the PC3 was always negative and during many days, less than minus two standard deviations below the mean. The second peak flow in magnitude occurred in 6 June, 1992 after a period initiated in 21 May with continuous negative values of the PC3 during many days below the mean minus one standard deviation. Similar was the case of the third peak flow that took place 6 January 1998, although in this case the PC3, while being persistently negative during the preceding days, was almost always over the mean minus one standard deviation.

As with PC2, this mode has not significant correlation with any of the indexes of Table 1, except a small one with AAO, sharing with Mode 2 the independence from hemispheric or global indexes as well as from SST (not shown).

\subsection{Fourth Mode}

Certain association with ENSO is suggested by the composite of the sea surface temperature (SST) anomaly with respect the mean daily value (Figure 9(a) and Figure 9(b)). In its positive phase there is a Niña like pattern that is more marked on the Niño $1+2$ region. In the negative phase, this association with El Niño SST results more evident, as the positive SST anomaly stretches over the equatorial band and negative anomalies extends from the subtropical latitude in the central Pacific Ocean to the southeast until the tip of the South American continent. However, though this mode presents inter-annual variability, this is concentrated at two significant peaks in its spectrum, at 2.5 and 11 years, but not at the main band of the ENSO frequencies, between 3.5 and 8 years. In addition, this mode presents almost significant bands in the frequencies near 40 and between 50 and 80 days (Figure 4(d)). 


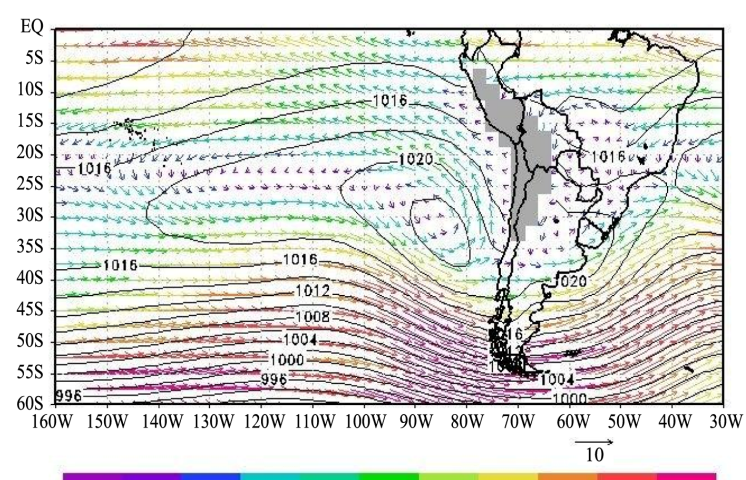

(a)

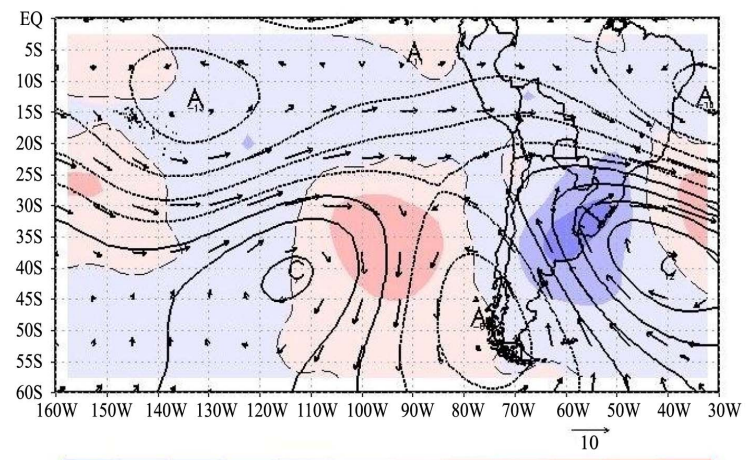

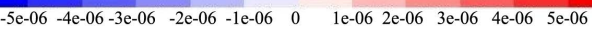

(c)

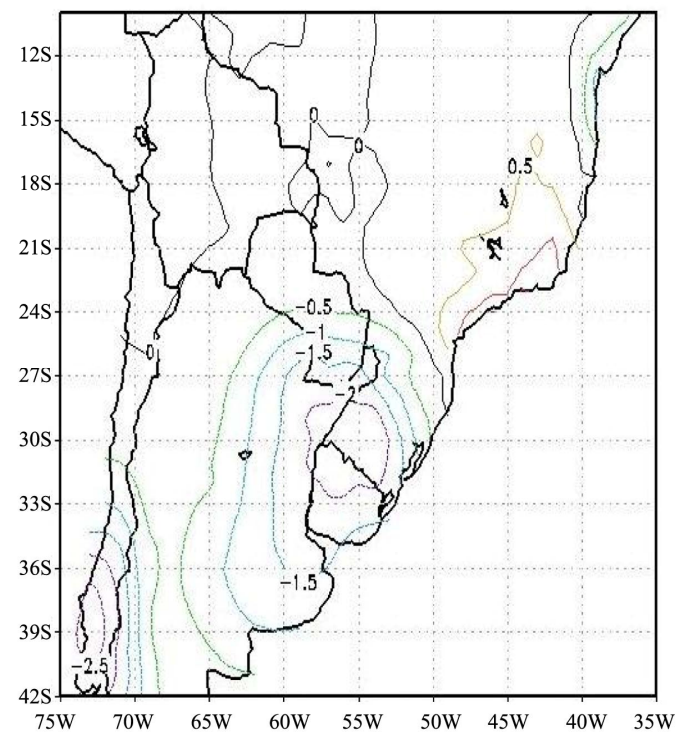

(e)
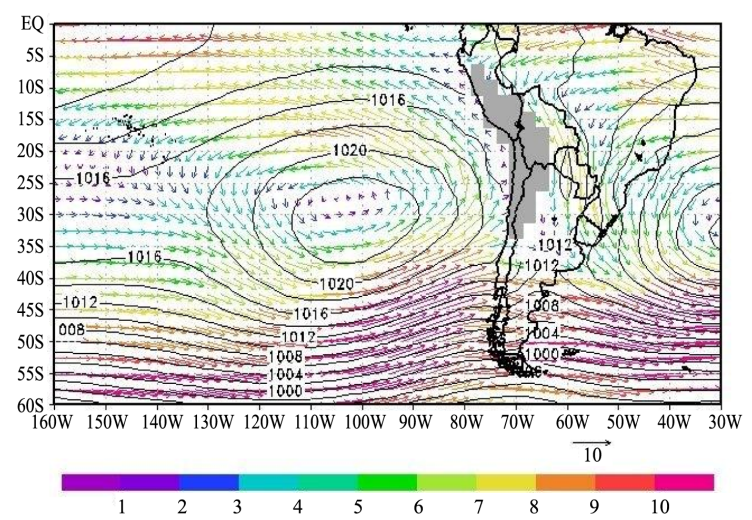

(b)

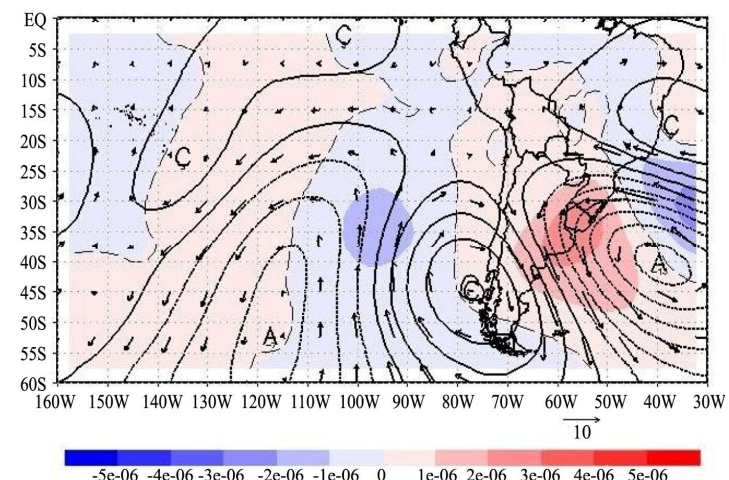

(d)

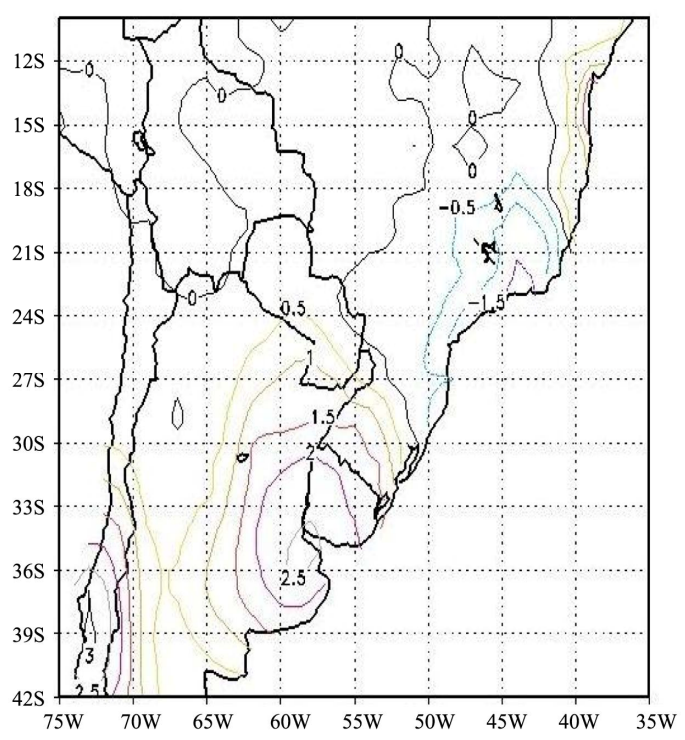

(f)

Figure 8. Same as Figure 6, but for Mode 3.

While the second and the third mode describe the simultaneous zonal shift of the ocean subtropical highs to the west or to the east, this mode depicts how these highs simultaneously approach to the continent in one phase and retreat farther of it in the other. In the composite of the positive phase, both anticyclones are displaced towards the continent (Figure 9(c) and Figure 9(d)). They are also displaced toward the south as in summer time with a similar intense western flow south of the continent. During summer months, the subtropical circulation 


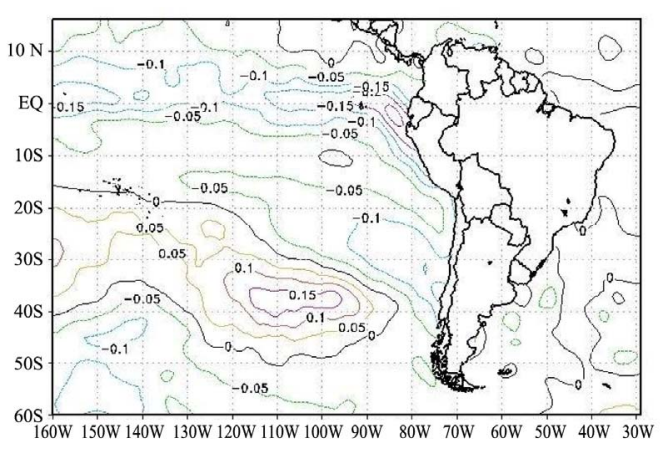

(a)

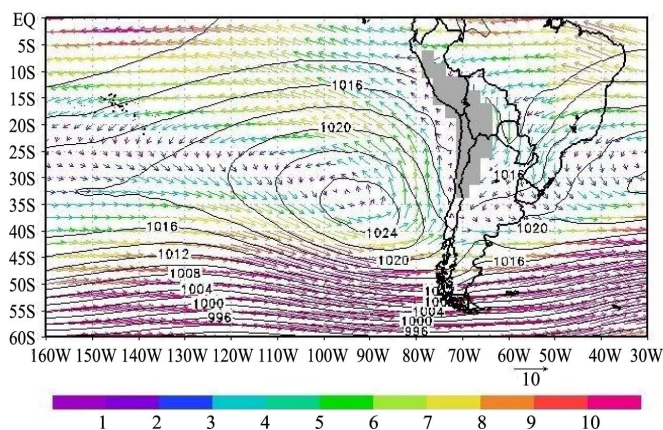

(c)

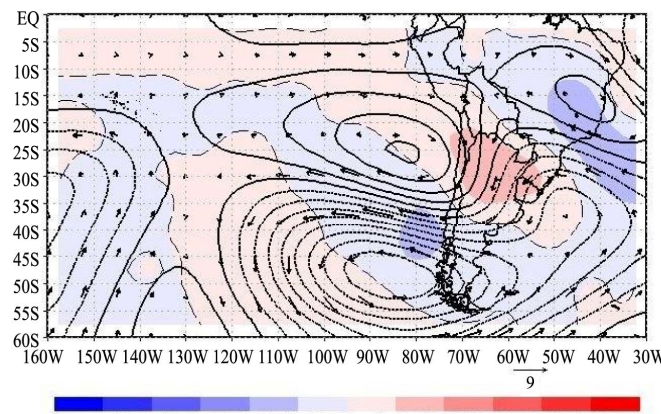

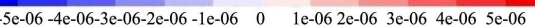

(e)

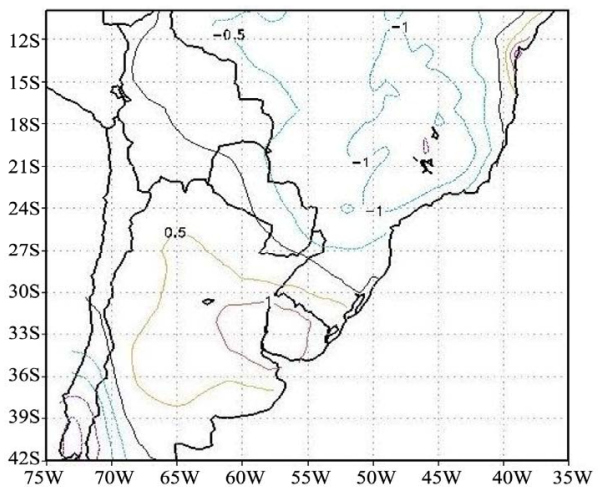

(g)

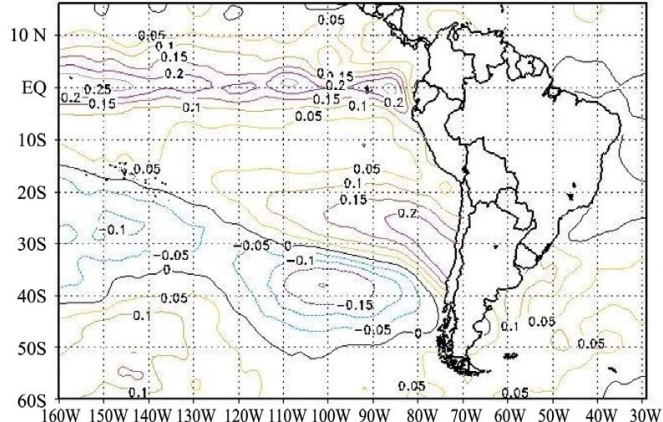

(b)

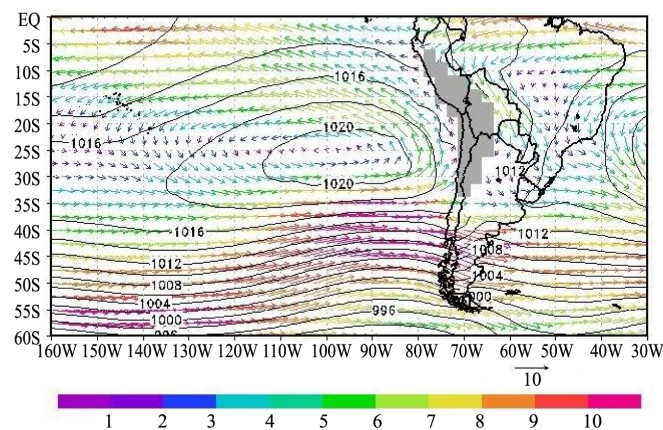

(d)

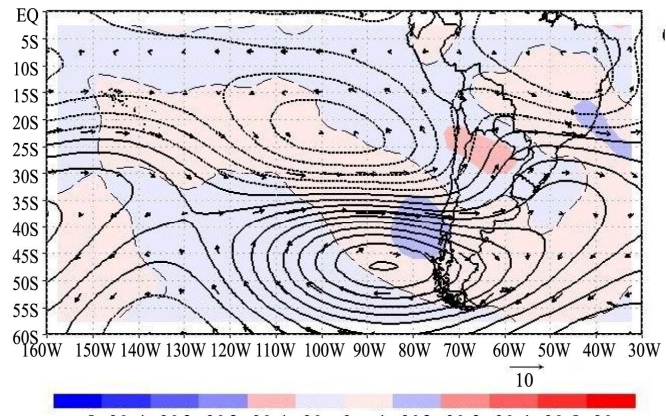

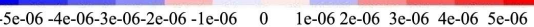

(f)

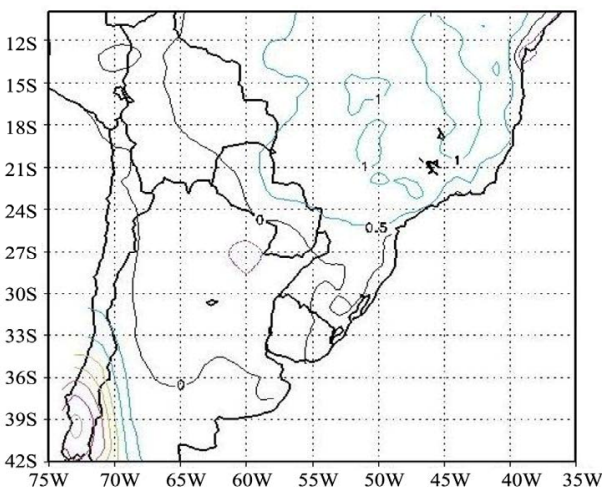

(h)

Figure 9. Positive (left) and negative (right) phase composites of Mode 4 of daily SST anomalies (top), sea level pressure and $850 \mathrm{hPa}$ wind components (middle top); anomalies of stream function (C: cyclonic; A: anticyclonic circulation) and divergence/convergence (light blue/light red) fields at $200 \mathrm{hPa}$ (middle bottom) and precipitation daily anomalies in mm/day (bottom). SST in Celsius degrees; sea level pressure in $\mathrm{hPa}$; wind components and wind anomalies in $\mathrm{m} / \mathrm{s}$. 
coincides with the typical one associated to the negative phase of SACZ. The composite of the negative phase shows the subtropical highs circulation farther from the continent than in the average, their latitude is more of the winter season, but the flow from the tropical continent converging with the flow from the northeast in the SACZ region is typical of the positive phase of this system during summer when the SACZ is southward of its mean position [57].

The composites of the upper tropospheric stream function anomalies of this mode do not present the classical and the opposed PSA-like wave trend that are associated to the two extreme phases of ENSO (Figure 9(e) and Figure 9(f)); what is more, contrary to what be expected according to the association of these phases with the ENSO SST patterns, near and over the continent the anomaly stream function fields are almost in opposite phase to those typical of La Niña (El Niño) for the positive (negative) phase [38] (Figure 9(a) and Figure 9(b)). The upper level convergence is consistent with the stream function anomalies and so, the precipitation anomalies, although not very important, are also opposite in sign to what may be expected from the respective association with the phases of this mode with La Niña and El Niño (Figure 10(g) and Figure 10(h)). Consistent with the association with the SST in the Pacific Ocean, this mode has a tendency to be more associated with La Niña (El Niño) when is over one standard deviation positive (negative) than with the El Niño (La Niña) although appears indistinctly at any phase of ENSO (Table 2).

Since this mode presents variability of frequencies corresponding to periods of 40 to 90 days, it is likely that the opposite, or at least considerably different to the average behavior of the precipitation in SCSA during El Niño and La Niña phases takes place during such periods indicating breaks of the typical ENSO circulation.

PC4 is positive and significantly correlated with the MJO indexes and shares their frequency of near 40 days. In addition to the possible connection with the break periods on the typical ENSO circulation in both extreme phases, the MJO has other impacts on the SCSA climate through its influence on the SACZ variability that, as shown, it is related to the forth mode. For instance, Liebmann et al. [59] argued that the MJO tends to modulate the phase of the mid latitude synoptic disturbances affecting the SACZ and Carvalho et al. [26] determined that an intense SACZ most often persists during the end of the MJO life cycle.

The correlation of PC4 with the AAO is weak and may be due to the connection between this index and the SST of El Niño regions [26].

\subsection{Fifth Mode}

The more striking feature of SLP and $850 \mathrm{hPa}$ wind field composites of the positive (negative) phase is the latitude of both, the Pacific and Atlantic highs centers, typical of the summer (winter) time (Figure 10(a) and Figure 10(b)). However, the cases corresponding to the positive (negative) phase are more likely to occur in late winter and spring (summer) (Figure 3(e)) when the mean latitude of the anticyclones is more to the north (south). Thus, this mode is capturing the anomalous latitude of the anticyclone circulation that sometimes happens during those seasons.

In the positive phase, the composite of $200 \mathrm{hPa}$ stream function shows a strong cyclonic anomaly located over central Argentina, and an anticyclonic anomaly over the northeast of SA (Figure 10(c)). Contrary to what happens at lower levels, the upper tropospheric circulation has a positive anomaly of the westerly flow over subtropical latitudes, proper of the winter and spring time. Consistent with the streamfunction field, at $200 \mathrm{hPa}$ there

Table 2. Association (cases over/under 1 standard deviation) of positive and negative phases of Mode 4 with ENSO events and SST in the Pacific Ocean.

\begin{tabular}{|c|c|c|}
\hline & \multicolumn{2}{|c|}{ Mode } \\
\hline & $\mathrm{CP} 4+$ & CP4- \\
\hline Niño & 328 & 525 \\
\hline SST+ & 315 & 334 \\
\hline SST- & 302 & 255 \\
\hline Niña & 501 & 348 \\
\hline Total days & 1446 & 1462 \\
\hline
\end{tabular}




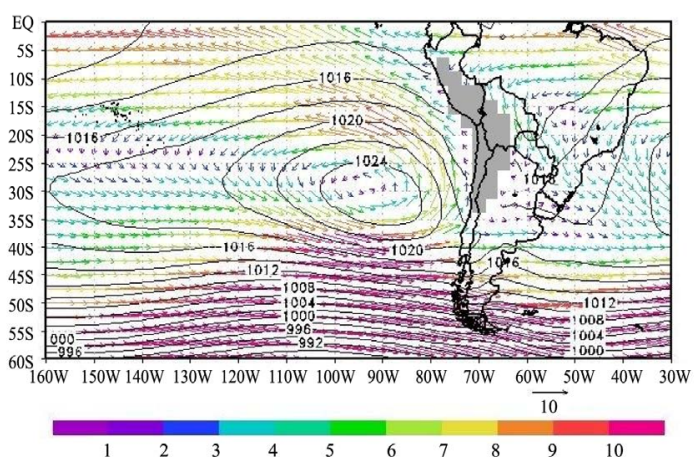

(a)

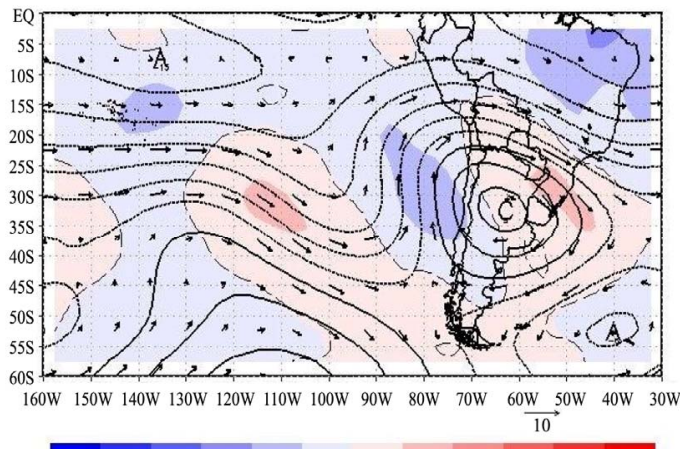

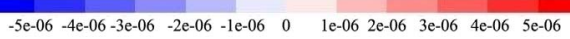

(c)

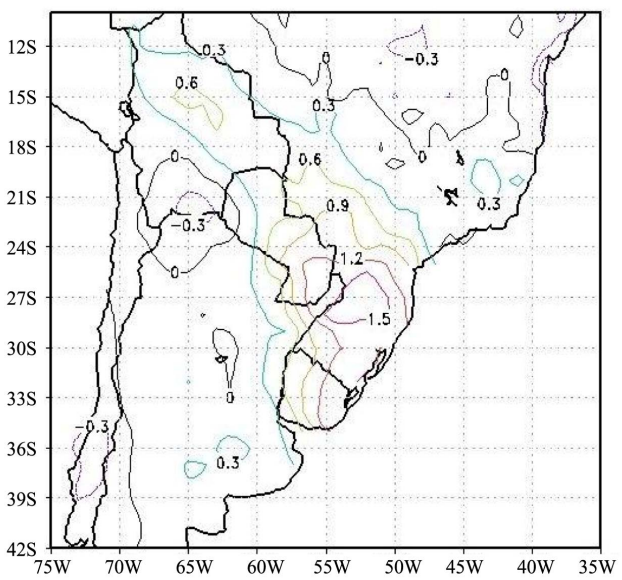

(e)
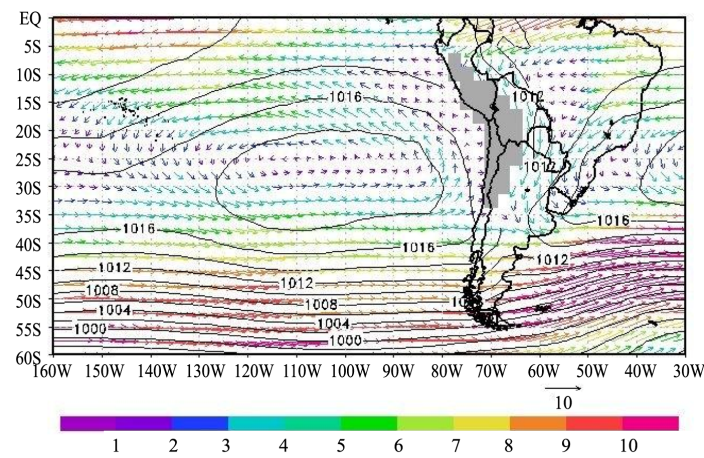

(b)

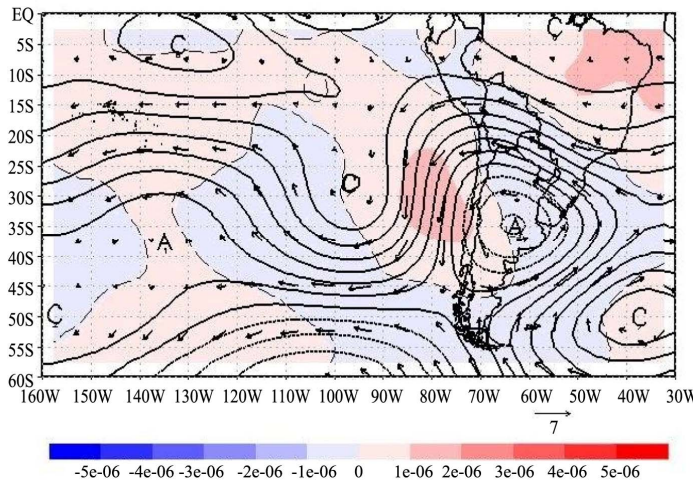

(d)

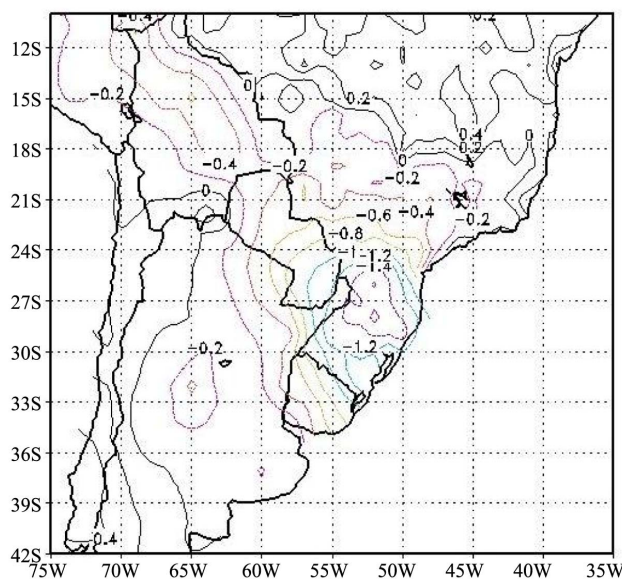

(f)

Figure 10. Same as Figure 6, but for Mode 5.

is divergence and an enhancement of precipitation over SESA and central Argentina and convergence over northeast Brazil, Chile and most of Patagonia (Figure 10(c) and Figure 10(e)). In the negative phase, the upper level anomaly circulation and the anomaly precipitation patterns are almost anti symmetric to those of the positive phase (Figure 10(d) and Figure 10(f)).

This mode does not have a significant frequency of occurrence, except at the annual one and at the lowest end of the spectrum, an indication of a trend (Figure 4(e)). The peak at year frequency indicates that in some years there are cases with an anomalous southern (northern) shift in both anticyclone centers in winter/spring (summer/early autumn). The importance of these shifts for the regional climate is that they are associated to important precipitation anomalies, particularly at SESA. 
PC5 is significantly correlated with the AAO index (Table 2). This may be due to the step increase that this PC had in the late 90's that was contemporary of a similar one of the AAO. This change is further discussed in Section 4.

\subsection{Sixth Mode}

In addition to significant peaks corresponding to periods between 45 and 100 days in its spectrum, the sixth mode presents considerable variability corresponding to the ENSO 3.4 frequencies at from 3.5 to 7 years, (Figure 4(f)), as well as a prominent one around 6 months, which although less pronounced is also present in the EN3.4 SST. The association with ENSO is also confirmed by the pattern of the composite of the sea surface temperature (SST) anomaly with respect the mean daily value (not shown) that are similar with small differences to those of Figure 9(a) and Figure 9(b); one of these differences is that in the case of negative phase, the SST anomaly in the EL Niño $1+2$ region reaches higher values, namely $0.45^{\circ} \mathrm{C}$. Finally, the upper level anomaly patterns of the stream function and the divergence fields are typical of the ENSO extreme phases (Figure 11(c) and Figure 11(d)).

While this mode shares with the fourth mode the fluctuation between both phases of simultaneous approaches to and retreats from to the continent of the circulation associated to the subtropical highs, in this case both anticyclones remain located over their average latitude (Figure 11(a) and Figure 11(b)). In the case of the negative phase associated with El Niño, there is a flow from the tropical continent that provides the water vapor, which together with the dynamical conditions causes the positive precipitation anomalies that are particularly important over SESA (Figure 11(f)). The warm low level flow over Central Argentina and SESA is important in the positive phase, but the convergence at upper levels prevails and the anomaly precipitation is negative over central Argentina and SESA (Figure 11(e)). As a conclusion, the typical regional circulation associated to both ENSO extreme phases is captured by this mode.

Contrary to what was found for mode 4, the correlation with SST El Niño regions of the PC6 is higher in the East than in the Central Pacific and as in the case of mode 4, correlations with MJO indexes are significant, but higher, Table 1. These correlations, together with the significant peak in the spectrum at 40 days, indicate that the MJO alters the regional circulation of the ENSO extreme phases (Table 2). This result is consistent with studies that indicate that the MJO may contribute to modify the overall intensity of El Niño episodes [60] [61].

\section{Discussion}

\subsection{Time Scales of the Regional Circulation Variability}

Since data was filtered to remove frequencies higher than those corresponding to 10 days, most of the synoptic variability was removed and the variance of each mode corresponds either to the annual cycle, or to the intra-annual variability not included in the annual cycle or to the inter-annual variability, the last including trends. Thus, what is discussed here is the distribution of the variance between these three ranges and excluding the synoptic scale.

For each PC, its annual cycle was calculated from the average over the 26 year period and from it, its corresponding variances at frequencies equal and over one year. Then for each PC, the intra-annual variance was calculated from the difference between the variance according to the spectrum for periods equal or below the year and the variance of the annual cycle in this part of the spectrum. The variance of the inter-annual scale of each PC was calculated from the integral of the spectrum for frequencies below that of a year. Table 3 shows how the variance is distributed in the three ranges for the first six leading modes and for their aggregated value for the first 40 modes. Although most of the PCs over number six represents noise, the aggregated variances up to mode 40 were included to show that when variance is calculated over $93 \%$ of its total value, its partition between the three ranges remains basically similar that when it is calculated with only the six leading modes.

The more relevant fact is that the intra-annual variance, which is no part of the annual cycle, accounts for most of the total variance, about $70 \%$. Except for the first mode which to a large extent represents the annual cycle, this intra-annual variance accounts for $67 \%$ to $89 \%$ of the other five leading modes. But even for the first mode, the intra-annual variance as defined here carries almost a third of the variance. In comparison, the variance of the inter-annual variability is small, accounting $7 \%$ to $9 \%$ of the total and being concentrated in modes 1 and 5 , which as will be shown in next section include in this variance a significant trend and a jump respectively. 


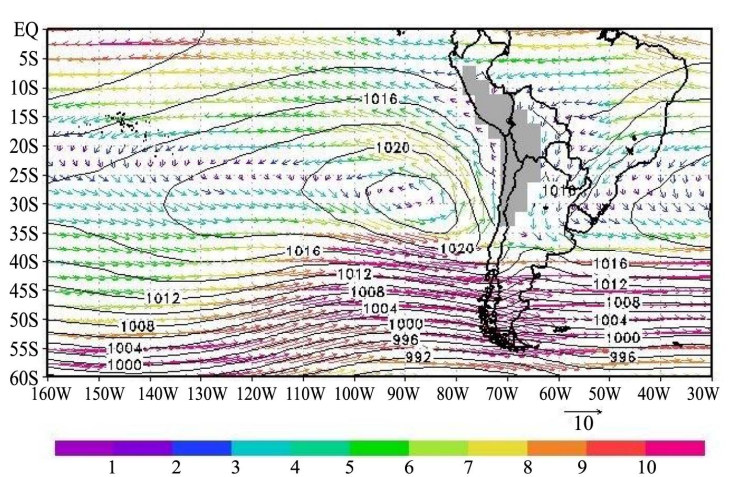

(a)

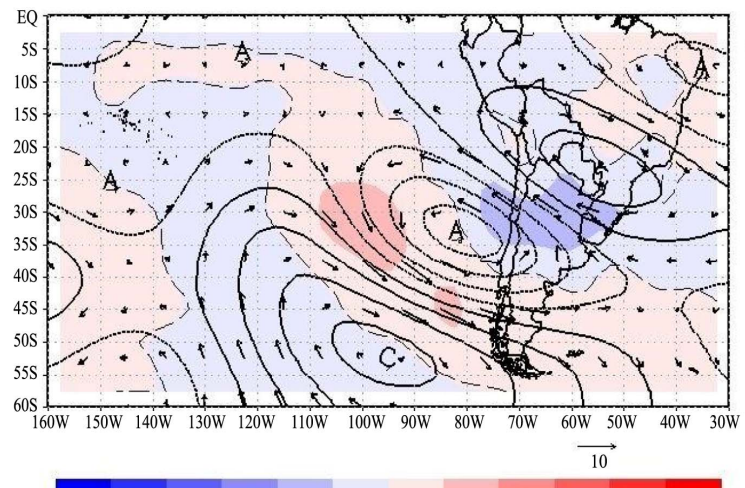

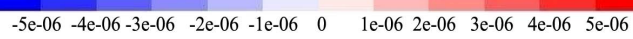

(c)

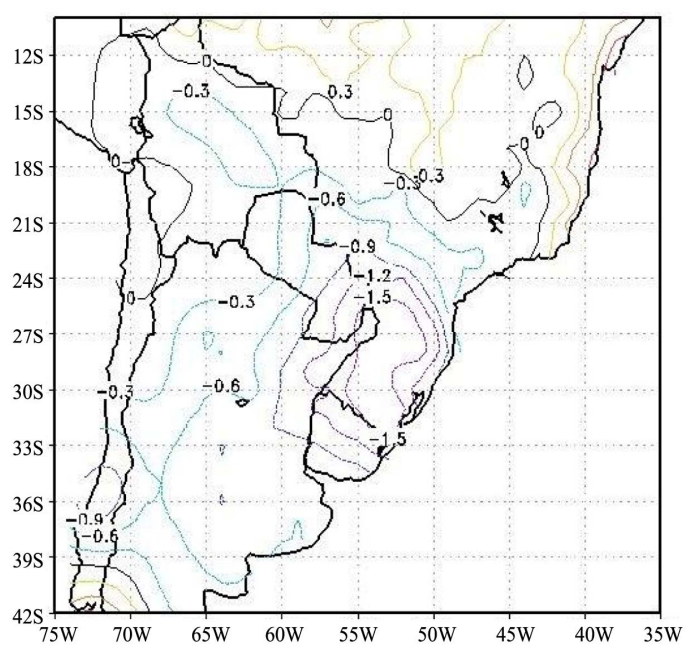

(e)

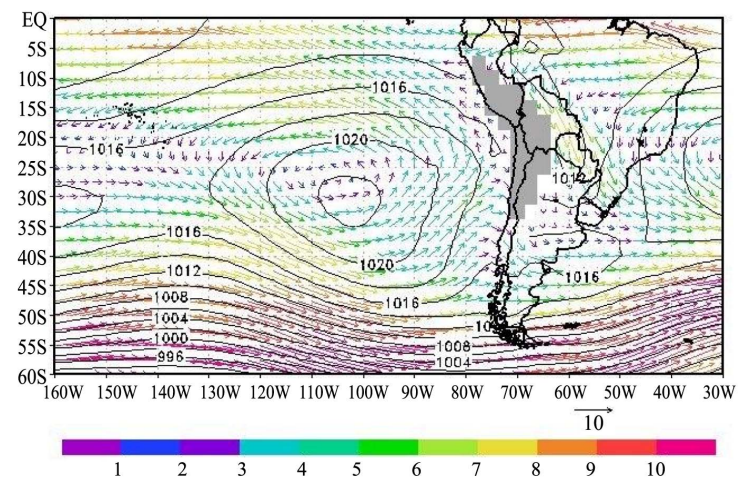

(b)

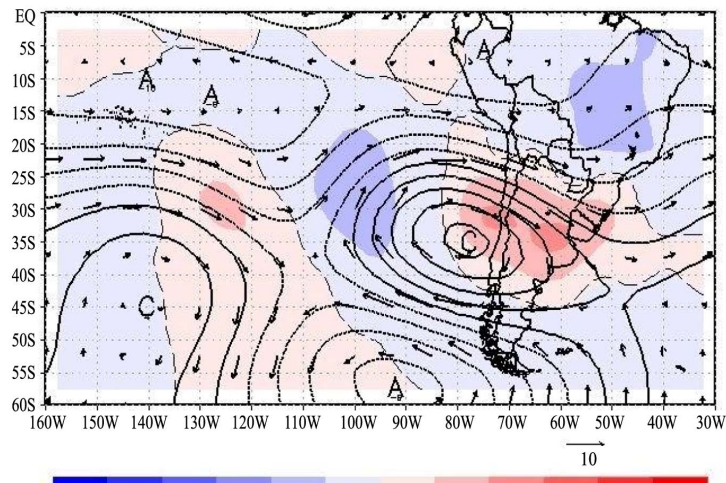

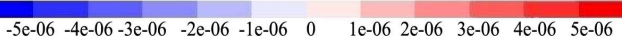

(d)

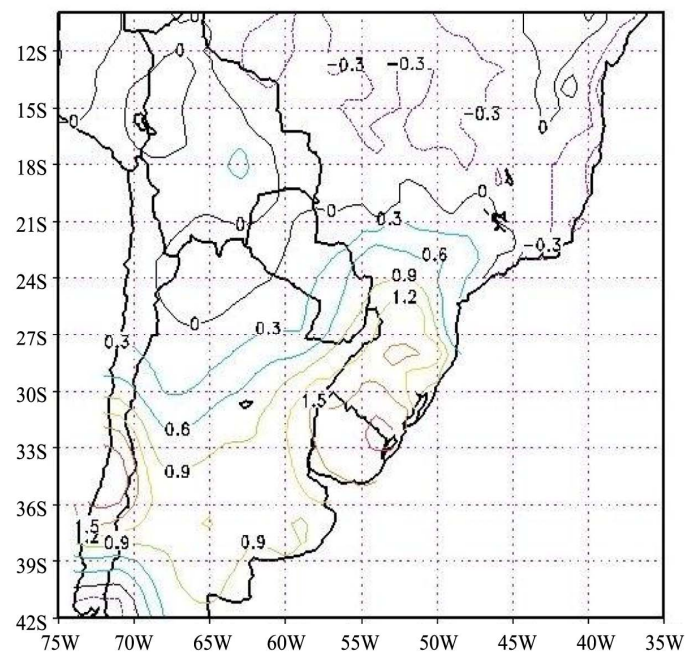

(f)

Figure 11. Same as Figure 6, but for Mode 6.

This partition implies that the predictability of regional climate at scales of a month or more is critically dependent on to what extent this intra-annual variability is driven or not by internal atmospheric variability.

\subsection{Trends and Jumps}

Winter temperature over central and eastern Argentina has been increasing during recent years. The mean areal temperature calculated from CRU archives for the region enclosed by $21^{\circ}-33^{\circ} \mathrm{S}$ and $55^{\circ}-65^{\circ} \mathrm{W}$ for the period 
Table 3. Distribution of the variance over the annual, the intra and the inter-annual scales for the first six leading modes and for their aggregated value for the first 6 and 40 modes. In brackets, for each mode the percentage variance in each scale.

\begin{tabular}{|c|c|c|c|c|c|c|c|}
\hline \multirow{2}{*}{$\begin{array}{c}\text { Mode } \\
1\end{array}$} & \multicolumn{2}{|c|}{ Annual cycle } & \multicolumn{2}{|c|}{ Intra-annual } & \multicolumn{2}{|c|}{ Inter-annual } & \multirow{2}{*}{$\begin{array}{l}\text { Total } \\
0.196\end{array}$} \\
\hline & 0.128 & $(60)$ & 0.062 & (32) & 0.016 & $(8)$ & \\
\hline 2 & 0.009 & (7) & 0.110 & (89) & 0.004 & (3) & 0.124 \\
\hline 3 & 0.008 & (8) & 0.088 & $(88)$ & 0.004 & (4) & 0.100 \\
\hline 4 & 0.007 & $(10)$ & 0.063 & $(85)$ & 0.004 & (6) & 0.075 \\
\hline 5 & 0.009 & $(15)$ & 0.041 & $(67)$ & 0.012 & (19) & 0.061 \\
\hline 6 & 0.003 & (5) & 0.049 & (89) & 0.003 & (6) & 0.055 \\
\hline First 6 leading modes & 0.154 & $(25)$ & 0.413 & $(68)$ & 0.043 & (7) & 0.611 \\
\hline First 40 leading modes & 0.184 & $(20)$ & 0.662 & (71) & 0.080 & (9) & 0.927 \\
\hline
\end{tabular}

May-September has a remarkable positive trend of $0.024^{\circ} \mathrm{C} /$ year during $1981-2006$. This means an end to end increase of $0.6^{\circ} \mathrm{C}$, well over the global trend and therefore presumable related to regional drivers.

The annual average of PC1 also shows a positive trend (significant at 95\% level), Figure 12(a), which basically comes from winter months. The number of annual cases over (below) the average plus (minus) one standard deviation is presented in Figure 12(b) and Figure 12(c); there is a positive (negative) and significant trend in the cases corresponding to the positive (negative) phase of Mode 1 superposed to a noticeable interdecadal variability. The positive phase predominates during winter months and, as explained in Section 3, distinguishes from the average winter in a marked northward low level flow over central and eastern Argentina. This flow brings warm air to this region and so, the mean areal temperature calculated from for the region above described for the period May-September has a strong annual correlation with PC4, namely 0.76 . This correlation is still high and significant, 0.72 , when both series that have significant positive trends are detrended. This means that there is a relationship between both variables, which does not depend of an eventual casual coincidence of trends. At the same time, this fact, together with the physics associated, implies that this regional temperature trend is at least partially due to the change in the circulation associated to Mode 1. This does not allow discarding global warming as the main driver of this local warming, since it may be also the cause of the local circulation trend.

The annual means of PC5 are shown in Figure 13(a). Since 1997/98 there is a jump. Before then, the mean winter/spring values were small, but afterward became greater and always positive, determining the annual values. This jump also appears in summer/early autumn, but now from definite negative values to small ones. These opposite jumps in the mean seasonal PC5 values are represented in its spectrum as an annual frequency (Figure 4(e)). The jump is also noticeable in the number of annual cases over (below) the average plus (minus) one standard deviation as shown in Figure 13(b) and Figure 13(c).

The jump in Mode 5 after the second half of the 90 s implies that afterwards there were more frequent cases in winter/spring with an anomalous shift to the south and less frequent cases with an anomalous northward shift in summer/autumn, reflecting a southward shift in the low level regional circulation. This shift was reported by Escobar et al. [62].

An almost simultaneous jump in the late 90's was observed in the SST average of the North Atlantic between the equator and $70^{\circ} \mathrm{N}$ and its detrended index, the Atlantic Multidecadal Oscillation index (AMO). However, their monthly or annual values have small and no significant correlation with PC5 and therefore if there is some connection between PC5 and them, it may be only at multidecadal scale.

\section{Summary and Concluding Remarks}

A principal component analysis of the low level circulation for time scale ranging from intraseasonal excluding synoptic scale to inter-annual scale was performed over a domain centered in CSSA and including the neighboring ocean regions. The aim was to identify possible not yet described modes of variation and trends in circulation that may account for some of the observed changes in temperature and precipitation. The results indicate 


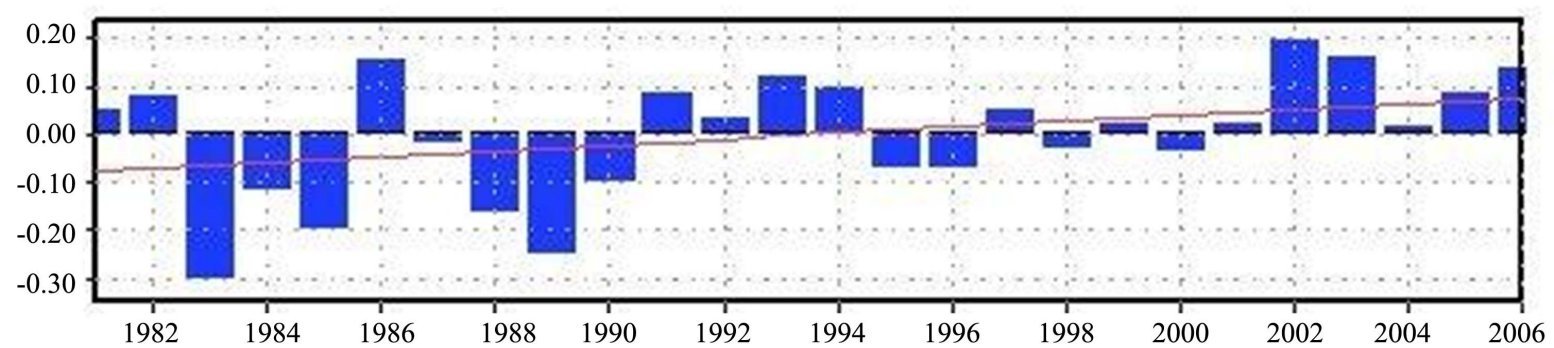

(a)

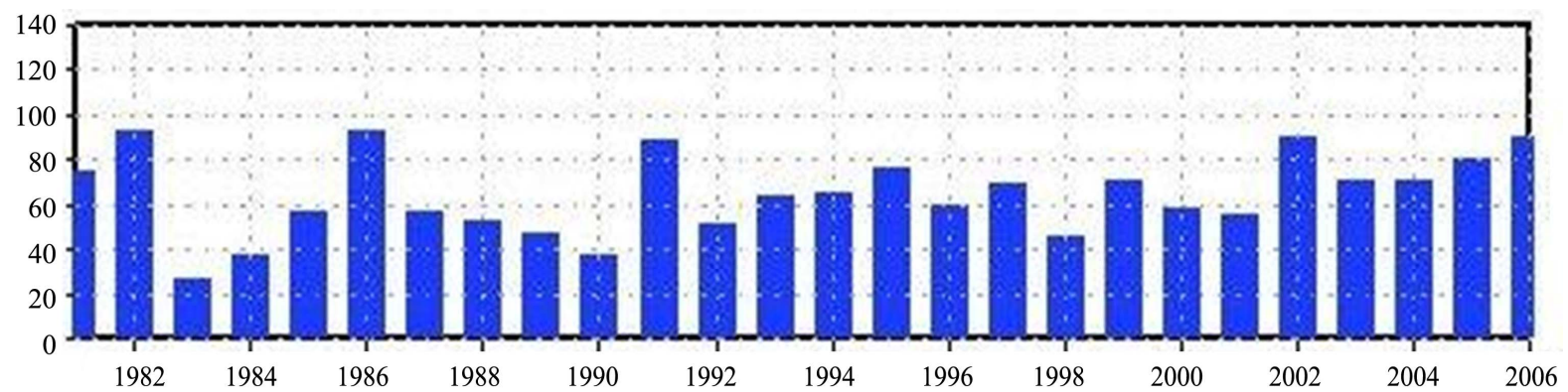

(b)

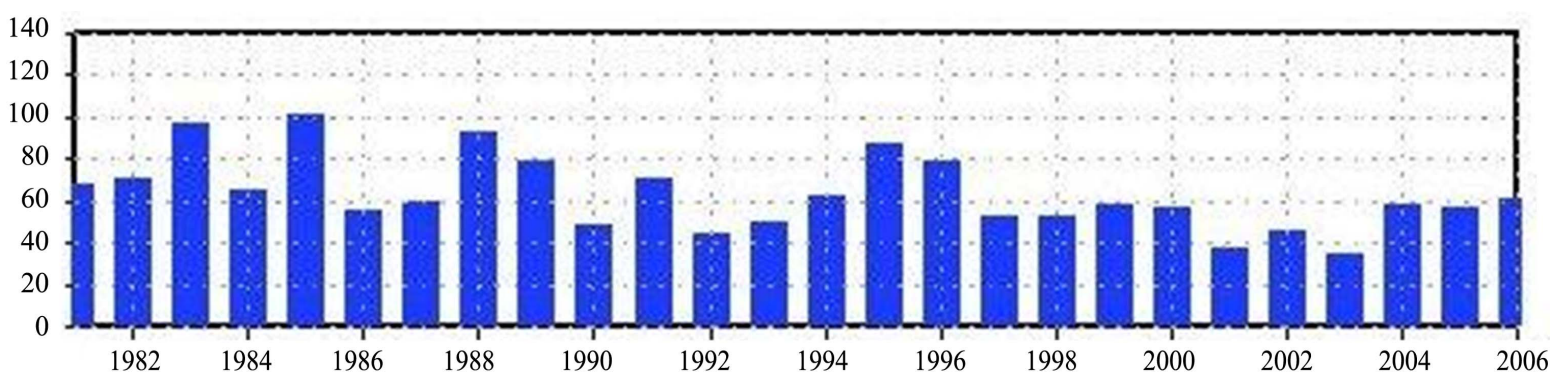

(c)

Figure 12. Annual average of Mode 1 (a); number of positive annual cases above $1 \sigma$ (b); and number of negative annual cases below $1 \sigma(\mathrm{c})$.

that regional precipitation changes are not described by a single mode.

Mode 1 in its positive phase has a similar circulation to the mean winter circulation, having however a localized difference with a northerly flow at low levels over Central Argentina that advects warmer temperature from the tropics. In fact, this mode correlates positively and significantly with surface temperature in Central Argentina and consequently its trend explains, at least, part of the winter warming observed in the last 3 decades in that region.

The second and third modes share significant peaks on the spectrum at approximately the same frequencies, annual and semiannual that are part of the annual cycle, but also at the frequencies of 40 and near 70 days. The low level circulation, more clearly, the location of the ocean highs has in both cases a simultaneous swing to the west in one phase and to the east in the other. The independence of other hemispheric or global indexes suggests that these modes reflect an independent regional mode of variability, whose extreme values create conditions either of drought or abundant precipitation that may cause floods over SESA. Not only, Modes 2 and 3 are basically independent of other regional or hemispheric modes, but also from SST and therefore it may be expected that their variability at the 40 to 70 day scale be part of the internal variability of the atmosphere. Their connection with precipitation made these modes relevant to the occurrence of drought and floods in part of SESA.

While the SST composite of the extreme cases of each phase of Mode 4 resembles La Niña and El Niño fields, their circulation and precipitation patterns over CSSA differ considerably from them. These two features indicate that this mode is related to the break periods in the two ENSO extreme phases. These breaks may be related 


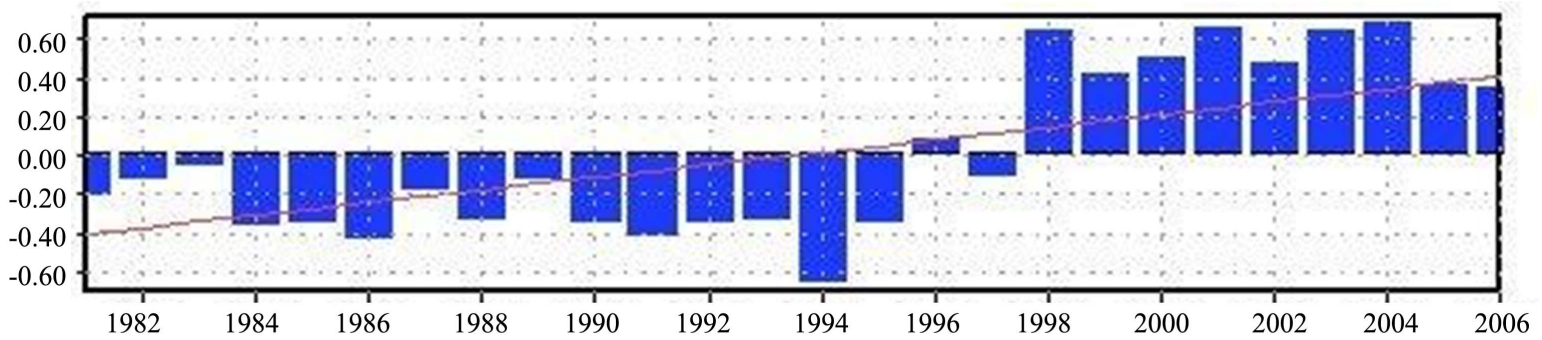

(a)

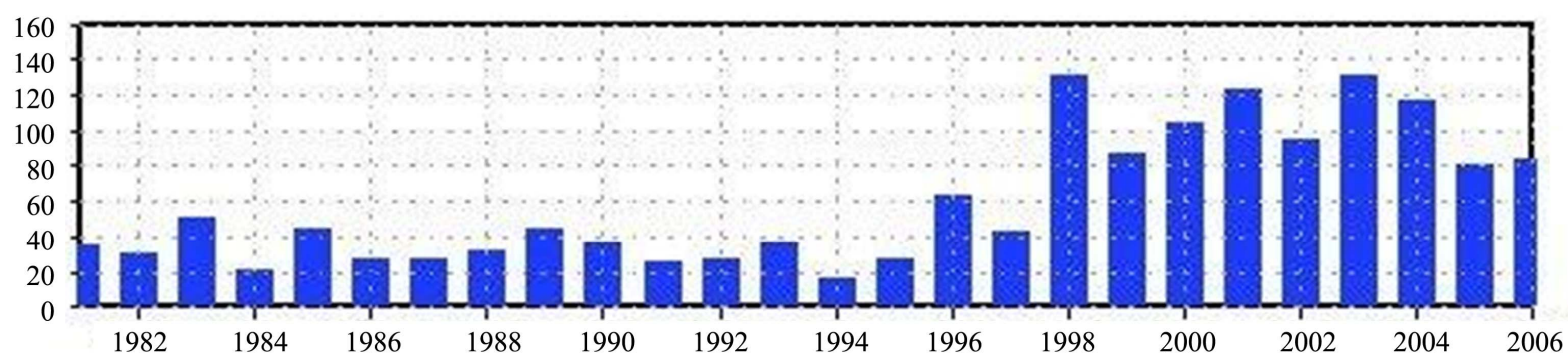

(b)

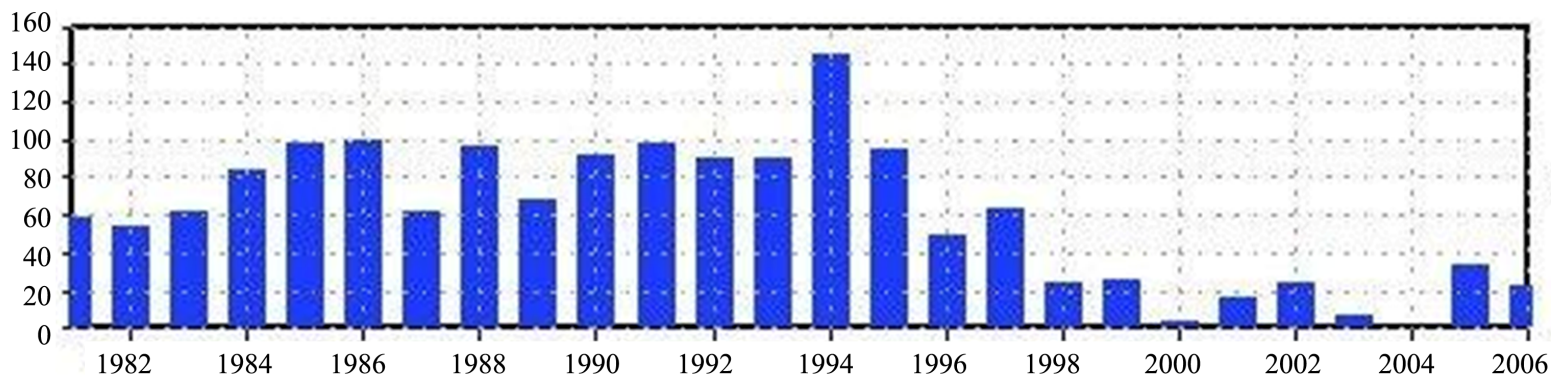

(c)

Figure 13. Same as Figure 12, but for Mode 5.

to the MJO since Mode 4 correlates well with the MJO indexes.

Mode 5 captures the cases when according to the season both Pacific and Atlantic heights are anomalous displaced in latitude of its annual average, namely to the south in winter and early spring and to the north in summer. This mode present a jump in the second half of the 1990 decade with a substantial increase of cases with a anomalous southern position of both heights in late winter and spring and less cases in summer where the mean latitude of the anticyclones are more to the north of its average latitude. This jump is consistent with a southward shift in the low level regional circulation as reported by [62]. Mode 6 describes the main features of the well known relation between ENSO and climate in CSSA, not adding anything new.

Modes 2 to 6 have most of their variance in the intra-annual scale, not included in the annual cycle, which as a result accounts for about $70 \%$ of the total variance, while the inter-annual scale has, at most, one digit percent. Modes 4, 5 and 6 have variability related to SSTs, but Modes 4 and 6 relation is with El Niño SST signal whose variance is known to be most in the inter-annual scale. Hence, most of the intra-annual variance of Modes 4 and 6 is not directly related to SST variability. Mode 5 shares a similar jump with the Atlantic Multidecadal Oscillation in the late 90's, but their correlation does not permit to infer some link beyond this simultaneous jump. Thus, a large proportion of variance that is in the intra-annual scale is not directly related to SST variability, what may represent a limitation to the climate predictability of the region.

\section{References}

[1] Zhou, J.Y. and Lau, K.M. (1998) Does a Monsoon Climate Exist over South America? Journal of Climate, 11, 1020- 
1040. http://dx.doi.org/10.1175/1520-0442(1998)011<1020:DAMCEO >2.0.CO;2

[2] Marengo, J.A., Liebmann, B., Grimm, A.M., Misra, V., Silva Dias, P.L., Cavalcanti, I.F.A., Carvalho, L.M.V., Berbery, E.H., Ambrizzi, T., Vera, C.S., Saulo, A.C., Nogues-Paegle, J., Zipser, E., Seth, A. and Alves, L.M. (2010) Recent Developments on the South American Monsoon System. International Journal of Climatology, 32, 1-21. http://dx.doi.org/10.1002/joc.2254

[3] Gallego, D., Ribera, P., Garcia-Herrera, R., Hernández, E. and Gimeno, L. (2005) A New Look for the Southern Hemisphere Jet Stream. Climate Dynamics, 24, 607-621. http://dx.doi.org/10.1007/s00382-005-0006-7

[4] Virji, H., (1981) A Preliminary Study of Summertime Tropospheric Circulation Patterns over South America Estimated from Cloud Winds. Monthly Weather Review, 109, 599-610. http://dx.doi.org/10.1175/1520-0493(1981)109<0599:APSOST>2.0.CO;2

[5] Lenters, J.D. and Cook, K.H. (1999) Summertime Precipitation Variability over South America: Role of the LargeScale Circulation. Monthly Weather Review, 127, 409-431. http://dx.doi.org/10.1175/1520-0493(1999)127<0409:SPVOSA>2.0.CO;2

[6] Chen, T., Weng, S. and Schubert, S. (1999) Maintenance of Austral Summertime Upper-Tropospheric Circulation over Tropical South America: The Bolivian High-Nordeste Low System. Journal of Atmospheric Science, 56, 2081-2100. http://dx.doi.org/10.1175/1520-0469(1999)056<2081:MOASUT>2.0.CO;2

[7] Ferreira, N.J., Correia, A.A. and Ramirez, M.C.V. (2004) Synoptic Scale Features of the Tropospheric Circulation over Tropical South America during the WETAMC TRMM/LBA Experiment. Atmósfera, 17, 13-30.

[8] Kousky, V.E. and Gan, M.A. (1981) Upper Tropospheric Cyclonic Vortices in the Tropical South Atlantic. Tellus, 33, 538-551. http://dx.doi.org/10.1111/j.2153-3490.1981.tb01780.x

[9] Ramírez, M.C.V., Kayano, M.T. and Ferreira, N.J. (1999) Statistical Analysis of Upper Tropospheric Vortices in the Vicinity of Northeast Brazil during the 1980-1989 Period. Atmósfera, 12, 77-88.

[10] Mishra, S.K., Rao, V.B. and Gan, M.A. (2001) Structure and Evolution of the Large-Scale Flow and an Embedded UpperTropospheric Cyclonic Vortex over Northeast Brazil. Monthly Weather Review, 129, 1673-1688. http://dx.doi.org/10.1175/1520-0493(2001)129<1673:SAEOTL $>2.0 . C O ; 2$

[11] Greco, S., Swap, R., Garstang, M., et al. (1990) Rainfall and Surface Kinematic Conditions over Central Amazonia during ABLE 2B. Journal of Geophysical Research, 95, 17001-17014. http://dx.doi.org/10.1029/JD095iD10p17001

[12] Li, W. and Fu, R. (2006) Influence of Cold Air Intrusions on the Wet Season Onset over Amazonia. Journal of Climate, 19, 257-275. http://dx.doi.org/10.1175/JCLI3614.1

[13] Paegle, J. (1998) A Comparative Review of South American Low-Level Jets. Meteorológica, 3, 73-82.

[14] Berbery, E.H. and Barros, V.R. (2002) The Hydrologic Cycle of the La Plata Basin in South America. Journal of Hydrometeorology, 3, 630-645. http://dx.doi.org/10.1175/1525-7541(2002)003<0630:THCOTL $>2.0$. CO;2

[15] Kodama, Y.M. (1992) Large-Scale Common Features of Subtropical Precipitation Zones (the Baiu Frontal Zone, the SPCZ, and the ZCAS). Part I: Characteristics of Subtropical Frontal Zones. Journal of the Meteorological Society of Japan, 70, 813-835.

[16] Carvalho, L.M., Jones, C. and Liebmann, B. (2002) Extreme Precipitation Events in Southeastern South America and Large-Scale Convective Patterns in the South Atlantic Convergence Zone. Journal of Climate, 15, 2377-2394. http://dx.doi.org/10.1175/1520-0442(2002)015<2377:EPEISS $>2.0$. CO;2

[17] Casarin, D.P. and Kousky, V.E. (1986) Anomalias de precipitação no sul do Brasil e variações na circulação atmosférica. Revista Brasileira de Meteorologia, 1, 83-90.

[18] Nogués-Paegle, J. and Mo, K.C. (1997) Alternating Wet and Dry Conditions over South America during Summer. Monthly Weather Review, 125, 279-291. http://dx.doi.org/10.1175/1520-0493(1997)125<0279:AWADCO >2.0.CO;2

[19] Doyle, M.E. and Barros, V.R. (2002) Midsummer Low-Level Circulation and Precipitation in Subtropical South America and Related Sea Surface Temperature Anomalies in the South Atlantic. Journal of Climate, 15, 3394-3410. http://dx.doi.org/10.1175/1520-0442(2002)015<3394:MLLCAP>2.0.CO;2

[20] Jones, C. and Carvalho, L.M. (2002) Active and Break Phases in the South American Monsoon System. Journal of Climate, 15, 905-914. http://dx.doi.org/10.1175/1520-0442(2002)015<0905:AABPIT >2.0.CO;2

[21] Jones, C., Waliser, D.E., Lau, K.M. and Stern, W. (2004) Global Occurrences of Extreme Precipitation and the Madden-Julian Oscillation: Observations and Predictability. Journal of Climate, 17, 4575-4589. http://dx.doi.org/10.1175/3238.1

[22] Grimm, A.M. and Ambrizzi, T. (2009) Teleconnections into South America from the Tropics and Extratropics on Interannual and Intraseasonal Timescales. In: Vimeux, F., Sylvestre, F. and Khodri, M., Eds., Past Climate Variability in South America and Surrounding Regions: From the Last Glacial Maximum to the Holocene, Springer, Apeldoorn, 159-191. http://dx.doi.org/10.1007/978-90-481-2672-9 7 
[23] Limpasuvan, V. and Hartmann, D.L. (1999) Eddies and the Annular Modes of Climate Variability. Geophysical Research Letters, 26, 3133-3136. http://dx.doi.org/10.1029/1999GL010478

[24] Gong, D. and Wang, S. (1999) Definition of Antarctic Oscillation Index. Geophysical Research Letters, 26, $459-462$. http://dx.doi.org/10.1029/1999GL900003

[25] Thompson, D.W.J. and Wallace, J.M. (2000) Annular Modes in the Extratropical Circulation. Part I: Month-to-Month Variability. Journal of Climate, 13, 1000-1016. http://dx.doi.org/10.1175/1520-0442(2000)013<1000:AMITEC >2.0.CO;2

[26] Carvalho, L.M., Jones, C. and Ambrizzi, T. (2005) Opposite Phases of the Antarctic Oscillation and Relationships with Intraseasonal to Interannual Activity in the Tropics during the Austral Summer. Journal of Climate, 18, 702-718. http://dx.doi.org/10.1175/JCLI-3284.1

[27] Kidson, J.W. (1988) Indices of the Southern Hemisphere Zonal Wind. Journal of Climate, 1, 183-194. http://dx.doi.org/10.1175/1520-0442(1988)001<0183:IOTSHZ>2.0.CO;2

[28] Rogers, J.C. and van Loon, H. (1982) Spatial Variability of Sea Level Pressure and 500mb Height Anomalies over the Southern Hemisphere. Monthly Weather Review, 110, 1375-1392. http://dx.doi.org/10.1175/1520-0493(1982)110<1375:SVOSLP >2.0.CO;2

[29] Silvestri, G.E. and Vera, C.S. (2003) Antarctic Oscillation Signal on Precipitation Anomalies over Southeastern South America. Geophysical Research Letters, 30, 2115-2118. http://dx.doi.org/10.1029/2003GL018277

[30] Vasconcellos, F.C. and Cavalcanti, I.F.A. (2010) Extreme Precipitation over Southeastern Brazil in the Austral Summer and Relations with the Southern Hemisphere Annular Mode. Atmospheric Science Letters, 11, 21-26.

[31] Mo, K. (2000) Relationships between Low-Frequency Variability in the Southern Hemisphere and Sea Surface Temperature Anomalies. Journal of Climate, 13, 3599-3610. http://dx.doi.org/10.1175/1520-0442(2000)013<3599:RBLFVI >2.0.CO;2

[32] Kousky, V.E., Kayano, M.T. and Cavalcanti, I.F.A. (1984) A Review of the Southern Oscillation: Oceanic-Atmospheric Circulation Changes and Related Rainfall Anomalies. Tellus, 36, 490-504. http://dx.doi.org/10.1111/j.1600-0870.1984.tb00264.x

[33] Ropelewski, C.F. and Halpert, M.S. (1987) Global and Regional Scale Precipitation Patterns Associated with the El Niño/Southern Oscillation. Monthly Weather Review, 115, 1606-1626. http://dx.doi.org/10.1175/1520-0493(1987)115<1606:GARSPP >2.0.CO;2

[34] Ropelewski, C.F. and Halpert, M.S. (1989) Precipitation Patterns Associated with the High Index Phase of the Southern Oscillation. Journal of Climate, 2, 268-284. http://dx.doi.org/10.1175/1520-0442(1989)002<0268:PPAWTH>2.0.CO;2

[35] Aceituno, P. (1988) On the Functioning of the Southern Oscillation in the South American Sector. Part 1: Surface Climate. Monthly Weather Review, 116, 505-524. http://dx.doi.org/10.1175/1520-0493(1988)116<0505:OTFOTS $>2.0$. CO;2

[36] Kiladis, G. and Diaz, H.F. (1989) Global Climatic Anomalies Associated with Extremes in the Southern Oscillation. Journal of Climate, 2, 1069-1090. http://dx.doi.org/10.1175/1520-0442(1989)002<1069:GCAAWE >2.0.CO;2

[37] Rao, V.B. and Hada, K. (1990) Characteristics of Rainfall over Brazil: Annual Variations and Connections with the Southern Oscillation. Theoretical and Applied Climatology, 42, 81-91. http://dx.doi.org/10.1007/BF00868215

[38] Grimm, A.M., Barros, V.R. and Doyle, M.E. (2000) Climate Variability in Southern South America Associated with El Niño and La Niña Events. Journal of Climate, 13, 35-58. http://dx.doi.org/10.1175/1520-0442(2000)013<0035:CVISSA $>2.0$. CO;2

[39] Barros, V.R and Silvestri, G.E. (2002) The Relation between Sea Surface Temperature at the Subtropical South-Central Pacific and Precipitation in Southeastern South America. Journal of Climate, 15, 251-267. http://dx.doi.org/10.1175/1520-0442(2002)015<0251:TRBSST>2.0.CO;2

[40] Grimm, A.M. (2011) Interannual Climate Variability in South America: Impacts on Seasonal Precipitation, Extreme Events and Possible Effects of Climate Change. Stochastic Environmental Research and Risk Assessment, 25, 537-554. http://dx.doi.org/10.1007/s00477-010-0420-1

[41] Kayano, M.T. (2003) A Note on the Precipitation Anomalies in Southern South America Associated with ENSO Variability in the Tropical Pacific. Meteorology and Atmospheric Physics, 84, 267-274. http://dx.doi.org/10.1007/s00703-002-0599-x

[42] Vera, C., Silvestri, G.E., Barros V.R. and Carril, A. (2004) Differences in El Niño Response over the Southern Hemisphere. Journal of Climate, 17, 1741-1753. http://dx.doi.org/10.1175/1520-0442(2004)017<1741:DIENRO >2.0.CO;2

[43] Díaz, A., Studzinski, C.D. and Mechoso, C.R. (1998) Relationships between Precipitation Anomalies in Uruguay and Southern Brazil and Sea Surface Temperature in the Pacific and Atlantic Oceans. Journal of Climate, 11, 251-271. http://dx.doi.org/10.1175/1520-0442(1998)011<0251:RBPAIU>2.0.CO;2 
[44] Camilloni, I. and Barros, V.R. (2004) South Atlantic Sea Surface Temperature and Its Relation with the Paraná River Discharges during El Niño 1982-83 and 1997-98. Revista Brasileira de Meteorologia, 19, 35-47.

[45] Castañeda, E. and Barros, V.R. (1994) Las tendencias de la precipitación en el Cono sur de América al este de los Andes. Meteorologica, 19, 23-32.

[46] Barros, V.R., Castañeda, E. and Doyle, M.E. (2000) Recent Precipitation Trends in Southern South America East of the Andes: An Indication of Climatic Variability. In: Smolka, P.P. and Volkheimer, W., Eds., Southern Hemisphere Paleo- and Neoclimates, Springer, New York, 187-206. http://dx.doi.org/10.1007/978-3-642-59694-0_13

[47] Quintana, J. and Aceituno, P. (2006) Trends and Interdecadal Variability of Rainfall in Chile. Proceedings of the 8th ICSHMO, Foz do Iguacu, 24-28 April 2006, 371-372.

[48] Sturaro, G. (2003) A Closer Look at the Climatological Discontinuities Present in the NCEP/NCAR Reanalysis Temperature Due to the Introduction of Satellite Data. Climate Dynamics, 21, 309-316. http://dx.doi.org/10.1007/s00382-003-0334-4

[49] Bengtsson, L., Hodges, K. and Hagemann, S. (2004) Can Climate Trends Be Calculated from Reanalysis Data? Journal of Geophysical Research, 109, 1984-2012. http://dx.doi.org/10.1029/2004JD004536

[50] Kanamitsu, M., Ebisuzaki, W., Woollen, J., Yang, S.K., Hnilo, J.J., Fiorino, M. and Potter, G.L. (2002) NCEP-DOE AMIP II Reanalysis (R-2). Bulletin of the American Meteorological Society, 83, 1631-1643. http://dx.doi.org/10.1175/BAMS-83-11-1631

[51] Reynolds, R.W., Rayner, N.A., Smith, T.M., Stokes, D.C. and Wang, W. (2002) An Improved in Situ and Satellite SST Analysis for Climate. Journal of Climate, 15, 1609-1625. http://dx.doi.org/10.1175/1520-0442(2002)015<1609:AIISAS >2.0.CO;2

[52] Liebmann, B. and Smith, C.A. (1996) Description of a Complete (Interpolated) Outgoing Longwave Radiation Dataset. Bulletin of the American Meteorological Society, 77, 1275-1277.

[53] Duchon, C.E. (1979) Lanczos Filtering in One and Two Dimensions. Journal of Applied Meteorology, 18, $1016-1022$. http://dx.doi.org/10.1175/1520-0450(1979)018<1016:LFIOAT>2.0.CO;2

[54] Slepian, S. (1978) Prolate Spheroidal Wave Functions, Fourier Analysis and Uncertainty-V: The Discrete Case. The Bell System Technical Journal, 57, 1371-1430. http://dx.doi.org/10.1002/j.1538-7305.1978.tb02104.x

[55] Mann, M.E. and Lees, J.M. (1996) Robust Estimation of Background Noise and Signal Detection in Climatic Time Series. Climate Change, 33, 409-445. http://dx.doi.org/10.1007/BF00142586

[56] Cattell, R.B. (1996) The Scree Test for the Number of Factors. Multivariate Behavioral Research, 1, 245-276. http://dx.doi.org/10.1207/s15327906mbr0102_10

[57] Cunningham, C.C. and Cavalcanti, I.F.A. (2006) Intraseasonal Modes of Variability Affecting the South Atlantic Convergence Zone. International Journal of Climatology, 26, 1165-1180. http://dx.doi.org/10.1002/joc.1309

[58] Karoly, D.J. (1989) Southern Hemisphere Circulation Features Associated with El Niño-Southern Oscillation Events. Journal of Climate, 2, 1239-1252. http://dx.doi.org/10.1175/1520-0442(1989)002<1239:SHCFAW >2.0.CO;2

[59] Liebmann, B., Kiladis, G.N., Vera, C.S., Saulo, C. and Carvalho, L.M.V. (2004) Subseasonal Variations of Rainfall in South America in the Vicinity of the Low-Level Jet East of the Andes and Comparison to Those in the South Atlantic Convergence Zone. Journal of Climate, 17, 3829-3842. http://dx.doi.org/10.1175/1520-0442(2004)017<3829:SVORIS >2.0.CO;2

[60] Kessler, W.S. and Kleeman, R. (2000) Rectification of the Madden-Julian Oscillation into the ENSO Cycle. Journal of Climate, 13, 3560-3575.

[61] Zhang, C. and Gottschalck, J. (2002) SST Anomalies of ENSO and the Madden-Julian Oscillation in the Equatorial Pacific. Journal of Climate, 15, 2429-2445. http://dx.doi.org/10.1175/1520-0442(2002)015<2429:SAOEAT>2.0.CO;2

[62] Escobar, G., Camilloni, I. and Barros, V.R. (2003) Desplazamiento del anticiclón subtropical del Atlántico Sur y su relación con el cambio de vientos sobre el estuario del Río de la Plata (Shift of the Subtropical High of the South Atlantic and Its Relation with the Wind Changes over the Plata River Estuary). Proceedings of the 10th Latin American and Iberian Congress of Meteorology, La Habana, 3-7 March 2003. 
Scientific Research Publishing (SCIRP) is one of the largest Open Access journal publishers. It is currently publishing more than 200 open access, online, peer-reviewed journals covering a wide range of academic disciplines. SCIRP serves the worldwide academic communities and contributes to the progress and application of science with its publication.

Other selected journals from SCIRP are listed as below. Submit your manuscript to us via either submit@scirp.org or Online Submission Portal.
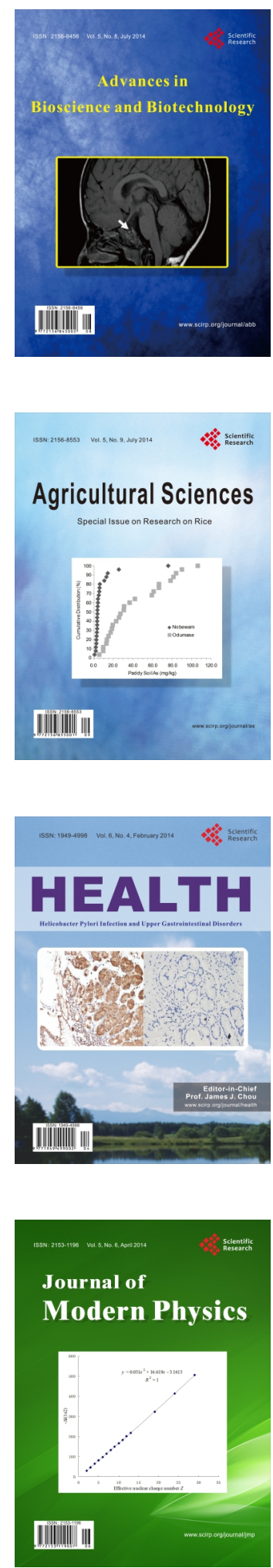
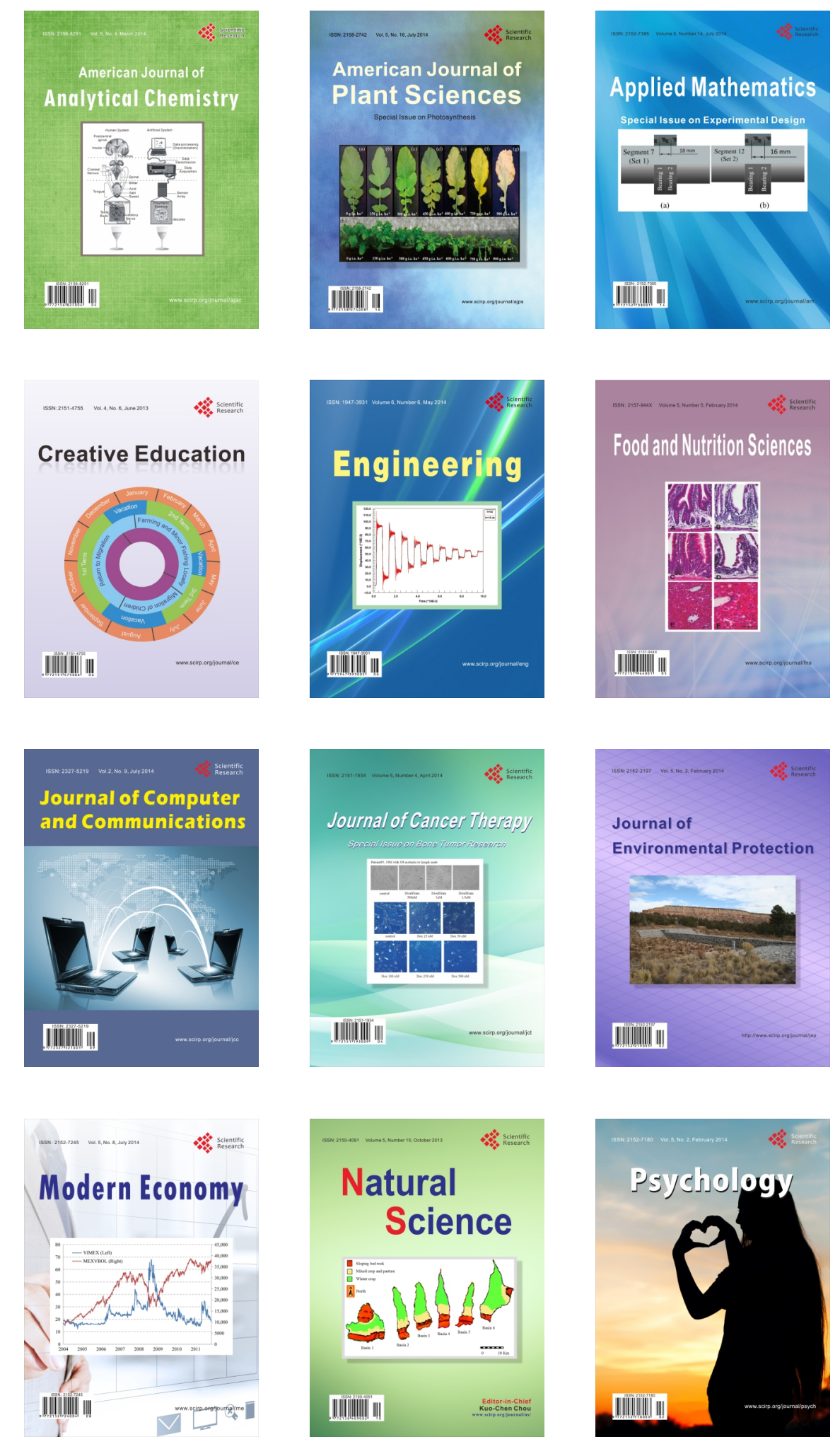